\title{
Reformar el gobierno de las Haciendas americanas antes de Gálvez: la actividad de la Contaduría General de Indias (1751-1776)
}

Anne Dubet

Université Clermont-Auvergne / Centre d'Histoire "Espaces et Cultures", Francia anne.dubet@uca.fr

Cita sugerida: Dubet, A. (2018). Reformar el gobierno de las Haciendas americanas antes de Gálvez: la actividad de la Contaduría General de Indias (1751-1776). Anuario del Instituto de Historia Argentina, 18 (2), e073. https://doi.org/10.24215/2314257Xe073

Recibido: 28 junio 2018 - Aceptado: 18 septiembre 2018 - Publicado: 07 diciembre 2018 (c) (1) (2) (2) Esta obra está bajo licencia Creative Commons Atribución-NoComercial-CompartirIgual 4.0 Internacional
$\mathrm{http}: / /$ creativecommons.org/licenses/by-nc-sa/4.0/deed.es_AR 


\title{
Reformar el gobierno de las Haciendas americanas antes de Gálvez: la actividad de la Contaduría General de Indias (1751-1776)
}

\author{
Reforming the government of the Spanish American Royal Treasury before Gálvez: the activity of the General \\ Accounting Office of the Indies (1751-1776) \\ Anne Dubet \\ Université Clermont-Auvergne / Centre d'Histoire "Espaces et Cultures", \\ Francia \\ anne.dubet@uca.fr
}

\section{Resumen:}

La Contaduría General de Indias, oficina creada en 1751, fue impugnada por el Consejo de Indias. Se analiza el significado político que le dieron los actores, favorables u hostiles, relacionándola con los demás órganos de gobierno de la Hacienda real. Conoce un relativo éxito cuando, desde fines de los 1760, participa en la dirección de las reformas indianas. Este éxito no se debe solo a una tendencia secular a consolidar la vía reservada de Indias: precisamente en aquellas fechas, el Secretario de Indias tiene una política ambivalente. Por eso se estudian la acción política y los proyectos de los actores.

Palabras Clave: Contaduría General de Indias, Vía reservada, Julián de Arriaga, Tomás Ortiz de Landazuri, Cardenal Julio Alberoni.

\section{Abstract:}

The General Accounting Office of the Indies, an office created in 1751, was challenged by the Council of the Indies. The political meaning given by the actors, favorable or hostile, is analyzed, relating it to the other governing bodies of the Royal Treasury. The new office has a relative success when, since the late 1760s, it participates in the direction of the reforms in Spanish America. This success is not only due to a secular tendency to consolidate the private channel of the Secretary at Spanish America: precisely at that time, this Secretary has an ambivalent policy. That is why the political action and the projects of the actors are studied.

KEYWORDS: General Accounting Office of Spanish America, Private channel, Cardinal Alberoni, Julián de Arriaga, Tomás Ortiz de Landazuri.

La Contaduría General de Indias se creó en 1751, durante el manejo del marqués de La Ensenada (1743-1754). Su conflictiva institucionalización constituye una reforma significativa del gobierno de las Haciendas indianas anterior a la era de José de Gálvez: "La nueva oficina es mucho más que un órgano de control técnico y judicial que se inscribiría en la continuidad de los existentes desde el siglo XVI. Según las lecturas habituales, este nuevo órgano habría sido poco eficiente en sus esfuerzos por mejorar la calidad del control contable, debiéndose esperar, para asistir a una modernización, a las reformas de Gálvez (en particular la creación de intendentes) y del contador general Francisco Machado Fiesco (la imposición de la teneduría de libros en partida doble desde 1784). Sin embargo, la creación del contador general obedece a un proyecto de reformas de Gálvez (en particular la creación de intendentes) y del contador general Francisco Javier Machado Fiesco (la imposición de la teneduría de libros en partida doble desde 1784) ${ }^{1}$. La creación del contador general obedece a un proyecto del equipo de Ensenada para enlazar con la "nueva planta" de Alberoni, quien pretendió confiar el gobierno de la Hacienda de Indias a la vía reservada y reducir la influencia del Consejo, idea que aparentemente tuvo poca aplicación antes de $1747^{2}$. Esto suscita un conflicto inmediato con el Consejo de Indias, que se traduce durante tres décadas en una vacilación entre dos denominaciones de la nueva oficina, Contaduría General de Indias y Contaduría General del Consejo de Indias. 
El empleo de la segunda en las principales instrucciones contables publicadas por la Contaduría hizo que la mayor parte de los historiadores no advirtieran la novedad institucional, por creer que se trataba de la Contaduría del Consejo, formalizada desde 1636 (Donoso Anes, 2009). El único en reparar en la novedad del título de Contador General y relatar algunos de los primeros momentos de conflicto entre la nueva oficina y el Consejo de Indias es Gildas Bernard (1972, pp. 121-155), en su estudio de las relaciones entre la Secretaría del Despacho de Indias y el Consejo, seguido en sus grandes líneas por Rafael García Pérez (1998, pp. 300-54) ${ }^{3}$. No obstante, Bernard considera que, después de la tensión inicial de los años 1758-1764, la Contaduría se impone como efecto de una tendencia general a la supremacía de la vía reservada y de los órganos responsables de la Hacienda (Bernard, 1972, p. 132). García Pérez, en su relato del mismo conflicto, también obvia la etapa 1766-1779 (García Pérez, 1998, pp. 326-30). Creo que se debe matizar esta lectura, dada la virulencia del conflicto. Así, intentaré explicar a qué proyecto político-institucional responde la Contaduría, cómo se impone en Madrid, qué papel desempeña la vía reservada en la búsqueda de una solución política, y qué espacio ocupa la nueva oficina en el conjunto de los órganos de gobierno de las haciendas hispanas.

Mi estudio no pretende ser exhaustivo. Se atiene al espacio de poder de la Contaduría General en Madrid, ofreciendo solo indicios sobre los cambios que provocó su creación en los órganos de gobierno de la Hacienda real residentes en las Indias, los cuales requieren una investigación propia. Se basa esencialmente en la documentación producida por la propia Contaduría, que quiso conservar una memoria de los conflictos en los cuales se fueron definiendo sus competencias. Dichos conflictos contituyeron una negociación tensa arbitrada por el Secretario del Despacho de Indias Julián de Arriaga (1754-1776) ${ }^{4}$. Cabe la posibilidad de que los contadores, ante dicho secretario, exagerasen estratégicamente la gravedad del enfrentamiento, pero la misma documentación comporta las respuestas del Consejo, sus secretarios y fiscales. Estas respuestas ofrecen una medida de la resistencia suscitada por la nueva oficina en Madrid y, por tanto, de la magnitud del cambio. Al mismo tiempo, el análisis de los reclamos salariales y estatutarios del contador general y de sus oficiales permite acceder a la concepción que estos actores tenían de su ubicación en el organigrama de los órganos de control y de gobierno de las Haciendas hispanas. Entretanto, la Contaduría no dejó de funcionar. El examen de algunos de los negocios que se le confiaron y la forma como participó en la puesta en obra de varias reformas permite completar la definición de su papel. Su existencia contribuyó a la recomposición de los equilibrios políticos en la corte y en las Indias en las décadas de 1760 y 1770. Primero, el desempeño de sus actividades de control judicial (revisión y juicio de cuentas) y administrativo (elaboración de estados de las diversas Haciendas americanas, reformas de la teneduría de libros y la organización de las cajas) alteró las relaciones entre los diversos responsables del gobierno de las Haciendas indianas -aspecto que se estudiará en otro artículo (Dubet y Sánchez Santiró, en prensa)-. En segundo lugar, al contador general, en su doble calidad de tal y de consejero de Indias, correspondió la iniciativa y la promoción de parte de los principales proyectos de reforma del gobierno de las Indias acometidos en los años 1760 y 1770 , e incluso puede considerarse que asumió en parte la dirección de las Haciendas indianas. Toda la cuestión consiste en saber cómo se relacionó con los sucesivos secretarios de Indias, Arriaga y Gálvez, interrogante que solo se resolverá parcialmente aquí, a la espera de futuras investigaciones.

\section{De Alberoni a Ensenada: un órgano de la vía reservada}

A 10 de noviembre de 1751, Fernando VI designa a Joaquín Ruiz de Porras como contador general de Indias, e invita a los contadores del Consejo de Indias en actividad a seguir ejerciendo bajo sus órdenes, mientras se les busca otro "destino". A su vez, los instiga a entregarle "todos los papeles de su archivo y pendientes". No se da en aquel entonces una planta a la nueva oficina; el nuevo titular presenta un proyecto de planta y ordenanzas solo un año después, lo que podría ser un indicio de la prisa con que Ensenada quiere imponer un nuevo marco constitucional ${ }^{5}$. Al organizar la cesión de papeles, el nombramiento sugiere entre líneas que la nueva 
Contaduría General es una oficina separada de la Contaduría del Consejo de Indias, destinada a sustituirla. Se explica de modo más nítido el proyecto político en 1752. Como expone Ruiz de Porras a Ensenada, el objetivo es "que con esta providencia tengan los ministros de Hacienda toda la autoridad que necesitan para que sus diligencias, celo y actividad produzcan los favorables efectos que se desean" ${ }^{6}$. La dimensión política es todavía más clara en un comentario posterior de su sucesor, Felipe de Altolaguirre, quien refiere en 1758 la voluntad de Ruiz de Porras de "erigir la Contaduría en tribunal supremo" ${ }^{7}$. En otros términos, se trata de crear una oficina exterior al Consejo de Indias -al contrario de la Contaduría existente-, para hacer de ella el instrumento de los "ministros de Hacienda".

La fórmula "Ministro de Hacienda", a la sazón, no es neutral. Para el gobierno peninsular se asocia al proyecto de consolidar la vía reservada en materia de Hacienda y, además, reunir en las manos de un solo individuo los empleos más importantes en el gobierno de la Hacienda, a saber, el de secretario del Despacho de Hacienda, responsable de la "distribución de fondos" -o sea del gasto y la relación con los hombres de negocios-, y el de superintendente general de la real Hacienda, quien ejerce su jurisdicción sobre la recaudación fiscal ${ }^{8}$. Precisamente, desde su llegada a las Secretarías de Hacienda, Guerra y Marina e Indias, y a la Superintendencia General de Hacienda en 1743, Ensenada reforzó las competencias de sus dos empleos de Hacienda, a expensas de los Consejos de Castilla, Hacienda, Indias y Cruzada y de algunas juntas ${ }^{9}$. Cuando comenté brevemente esta nueva creación institucional en 2016, pensé que Ruiz de Porras se proponía crear un empleo de Ministro de Hacienda de Indias, que estaría en las mismas manos que el empleo de ministro de Hacienda de España (Dubet, 2016a, pp. 44-48 ). Me pregunto ahora si también contemplaría la creación de un solo "Ministro de Hacienda" para el conjunto de los territorios de la Monarquía, o sea, una integración institucional del gobierno de todas. En efecto, el primer modelo de la Contaduría General de Indias es la reforma intentada en el marco de la Nueva Planta de Alberoni, que promovía esta integración en 1717.

Durante la segunda Nueva Planta posterior a la Guerra de Sucesión, no solo se consolidó la vía reservada -en particular en el gobierno de Indias- retirando al Consejo las materias de Guerra, Hacienda, Comercio y Navegación de América, para dejar "lo gubernativo, económico y providencial" a los secretarios del Despacho en el decreto de 20 de enero de 1717. El 20 de septiembre se aclaró el significado de la medida: 1) todas las órdenes expedidas por la vía reservada se podían ejecutar sin esperar a que el Consejo las firmara; 2) éste perdía la facultad de confirmar la distribución de encomiendas por parte de los virreyes, presidentes de audiencias y gobernadores, cuyas facultades también se veían mermadas, por tanto, quedando la cesión de encomiendas reservada al rey, mediante la vía reservada ${ }^{10}$; 3) asimismo, desaparecía provisionalmente la Cámara de Indias ${ }^{11}$. Además, el 2 de abril, se repartió la materia de Indias entre tres secretarios del Despacho: el de Estado o "negocios extranjeros", el de Guerra y Marina, y el de "Justicia, Gobierno Político y Hacienda de España e Indias”. Se integró así el gobierno de las Haciendas del conjunto de la monarquía ${ }^{12}$. A esta reforma de los órganos de dirección, la acompañó (1 de mayo) la reducción del número de secretarios de varios Consejos -aunque no el de Indias-, corolario de la de sus facultades ${ }^{13}$, y el de Indias perdió consejeros (Burgos Lejonagoitia, 2015, pp. 90-91). El mismo día, se reorganizaron los flujos de información contable, para lo que se crearon tres nuevas Contadurías Generales de la Razón (de Valores, de Distribución y de Millones). A partir de la absorción de las 11 contadurías de libros del Consejo de Hacienda debían recibir todas las relaciones y cuentas de los numerosos responsables del manejo del dinero del rey, y organizar el arrendamiento de rentas ${ }^{14}$. En una fecha indeterminada (por carecerse de monografías sobre el tema), estas Contadurías Generales se situaron debajo de la vía reservada y salieron de la órbita del Consejo de Hacienda ${ }^{15}$. Ahora bien, las de Valores y Distribución tenían competencia sobre el manejo de fondos en las Indias, por lo que en ellas debía tomarse la razón de todos los despachos relativos al pago de fondos y a créditos contra la real Hacienda, así como la de los "efectos de entrada y salida", del modo que le fue explicado al gobernador del Consejo de Indias y a sus Contadores ${ }^{16}$. En 1718, las reformas del Consejo de Hacienda, de la Tesorería General de España y de las intendencias buscaron consolidar el control de los secretarios del Despacho de 
Guerra y de Justicia, Gobierno Político y Hacienda sobre la distribución del dinero del rey en la España peninsular y sus islas (Dedieu, 2000; Dubet, 2015). En suma, la integración de las Haciendas de la Monarquía y el reforzamiento de la vía reservada en detrimento de los órganos colegiales concernían tanto a los órganos de decisión como a los de control contable, en un esquema concebido para el conjunto de la Monarquía. En la península, la llegada de nuevos agentes civiles de la vía reservada (como los intendentes, tesoreros provinciales y contadores principales) amenazaba a los responsables militares y a los concejos de las capitales de provincias. En las Indias, virreyes, presidentes y gobernadores perdían capacidad en la distribución de encomiendas.

Después de la caída de Alberoni (1719) se volvió a separar la materia de Indias, mediante la creación de una Secretaría de Marina e Indias en 1721, y se restableció la Cámara (Burgos Lejonagoitia, 2015, pp. 90-92). No obstante, no se abandonó todo su legado en lo concerniente a Hacienda. Al contrario, se reforzaron las competencias del ministro de Hacienda y se mantuvieron las estructuras que le permitían controlar la distribución de los fondos en el espacio peninsular -la red de agencias de la Tesorería Mayor, las intendencias de ejércitos y las tres Contadurías Generales (Dubet, 2015; Torres Sánchez, 2012)-. Al carecer de estudios sobre el trabajo cotidiano del secretario de Indias y sus relaciones con el Consejo de Indias en cuestiones de Hacienda en aquellas décadas, no sabemos cómo funcionaron ${ }^{17}$. De creer a Ensenada quien podría exagerar algo, dado el interés de Patiño por afirmar la vía reservada en tales cuestiones ${ }^{18}$-, el decreto de 1717 que reservara los negocios de Hacienda, Guerra, Marina y Comercio a la vía reservada no se aplicó (Dubet, 2016a, p. 112). En todo caso, en los años 1746-1754, para Ensenada y su grupo, el diseño institucional imaginado por Alberoni y sus colaboradores se convierte en la justificación de un giro político, tanto para el gobierno de Indias como para la España peninsular. Si, en el caso de Ruiz de Porras, antiguo cliente de un colaborador del cardenal, la referencia se podría explicar por una eventual implicación personal en la primera Nueva Planta (Dubet, 2016a), para los demás se trata de un modelo a seguir.

Así, en España, Ensenada se propone recoger el esquema de las intendencias y tesorerías de provincias sin tropas, remodelado en 1718 y abandonado en 1721. Aunque no consigue erigir agencias de la Tesorería General en las provincias, refuerza el control de la vía reservada sobre la información contable y la distribución de los fondos gracias a las nuevas intendencias de provincias y las Direcciones Generales de Rentas (con sus administradores provinciales), colocadas debajo de la autoridad directa del ministro de Hacienda (Dubet y Solbes Ferri: en prensa, cap. 3). En las Indias "revalida” el decreto de enero de 1717 a 18 de mayo de 1747, o sea que confirma que sigue teniendo validez, ya que en su opinión se dejó de aplicar. Además, como sabe que no podrá crear intendentes de provincias sin contar con el apoyo activo de los tres virreyes, decide transformar a los virreyes en superintendentes generales de la Hacienda de sus reinos respectivos (1747/1751), situados debajo del Secretario de Indias, o sea, hace de ellos agentes de la vía reservada ${ }^{19}$. Probablemente por esta razón Ensenada no acepta un proyecto que Altolaguirre atribuye a Ruiz de Porras, consistente en "inhibir de la Superintendencia de [Hacienda] a los virreyes”, idea radical afín a lo que intentara Alberoni (Dubet, 2016a). Aunque no se agregan las materias de Indias y España en una sola secretaría del Despacho de Hacienda, sí cabe enfatizar las analogías entre las políticas implementadas en ambas orillas del Atlántico. De hecho, Ensenada parece pensar en una forma de integración institucional, cuando en 1751 se propone dar nuevas ordenanzas a las Contadurías Generales en plural, oficinas que describió en 1749 como la "llave de la Hacienda" (Rodríguez Villa, 1878, pp. 77-83 y 113-143). Es probable que incluya en la lista a la de Indias. En la creación de ésta, el punto nodal es la analogía con las peninsulares, mencionada al nombrar a Ruiz de Porras:

Declaro que, en todas mis reales cédulas, despachos y demás instrumentos en que hubiesen de tomar razón los Contadores Generales de mi real Hacienda y el Contador General de Indias, se observe el mismo método, sin alteración alguna que se ha seguido hasta ahora entre aquellos y los Contadores de Indias ${ }^{20}$.

Para los defensores posteriores de la Contaduría General de Indias, la analogía es una evidencia o una reivindicación. En 1761, muerto Altolaguirre, su oficial mayor se vale de ella para justificar su derecho a sustituirle como interino $^{21}$. Pero la similitud entre las Contadurías Generales no es una cuestión técnica, 
sino política, como clarifica el tercer contador, Tomás Ortiz de Landazuri. La Contaduría General se sitúa fuera del Consejo de Indias, lo mismo que las instituidas en 1717 estaban fuera del de Hacienda: es "conforme al modo en que corren los ramos de [la Hacienda] y a los títulos que tienen las Contadurías Generales de la Distribución, Valores y Millones, pues ninguna se apellida del Consejo de Hacienda, porque en la realidad no lo son" ${ }^{22}$. En 1767, se vale del paralelo para solicitar la preeminencia de la Contaduría General de Indias sobre las tres otras y la de Cruzada. Debido a que el contador general es consejero de capa y espada del Consejo de Indias (desde abril de 1767), lo mismo que los tres primeros contadores generales lo son del de Hacienda, el orden de precedencia en la toma de razón debería ser el que rige para los Consejos ${ }^{23}$. En los mismos años se crea una tradición que valora la continuidad entre la defensa de la vía reservada de Indias por parte de Alberoni, Ensenada y Arriaga, tradición que los promotores de la Contaduría General de Indias utilizan para justificar sus facultades ${ }^{24}$.

En estas condiciones, la creación de la Contaduría General de Indias en 1751 sería uno de los últimos elementos de un diseño institucional que se empezó a construir en 1743, con una neta aceleración desde 1747-1749. Su objeto era poner en las manos del ministro de Hacienda de España y el secretario de Indias el manejo del dinero real en todos los territorios y, como instrumento de ello, el control contable sobre los mismos. No se llega a aplicar todo el proyecto y quedan en suspenso las ordenanzas para las Contadurías Generales (Aguirre, 1759). Después de 1754, los sucesores de Ensenada prolongan -con algunos acomodosgran parte de sus reformas hacendísticas (Baudot Monroy: 2017; Dubet y Solbes Ferri: en prensa). No obstante, el mantenimiento de la Contaduría General de Indias es una cuestión altamente conflictiva.

\section{UN NACIMIENTO CONTROVERTIDO}

Desde la creación de la Contaduría General de Indias, Ruiz de Porras se enfrenta a la resistencia pasiva de los Contadores del Consejo de Indias, obligados a trabajar bajo de sus órdenes, y al ostracismo de los consejeros. Ésta, sin duda, es la razón -a los dos meses de redactar un borrador de ordenanza- de su solicitud de jubilación, (diciembre de 1752), concedida en abril de $1753^{25}$. Un cuarto de siglo después, el contador en activo Machado Fiesco comenta que los secretarios del Consejo conservan el mismo "sistema" que el denunciado por su predecesor Ortiz de Landazuri, lo que podría corresponder a un momento en que dichos secretarios se aprovechan de la transición entre ambos contadores para recuperar mayor influencia ${ }^{26}$. Además, elogia a Ortiz de Landazuri por la tenacidad con que defendió "las regalías de su empleo" frente a secretarias que querían hacerse "árbitras en que llegue o no el caso de verse en este tribunal [la Contaduría General] los negocios de la mayor entidad e importancia”, y frente a los Fiscales del mismo Consejo que las apoyaron con "poca instrucción" ${ }^{27}$. Entretanto, el conflicto entre los contadores sucesivos y el Consejo de Indias conoce varias fases, y resulta particularmente agudo entre 1753 y mediados de la década de 1760. Interesa estudiar los argumentos de los actores para comprender en qué contribuyó la creación de la Contaduría General a modificar la forma de gobernar las Haciendas indianas. ${ }^{28}$

La primera fuente de tensiones es interna. Nace del descontento de los contadores y oficiales de la Contaduría del Consejo de Indias que se ven desplazados por la creación de la nueva oficina. Ruiz de Porras se quejó de su ausentismo, sus enfermedades políticas y su incompetencia. Altolaguirre reitera sus argumentos en 1757, y denuncia en particular la poca "inteligencia” y la ausencia de Juan Crisóstomo Bonavia, contador supernumerario desde 1732, y de Eugenio de Alfaro, también supernumerario desde 1737. Respecto de la mayoría de los demás, se puede lamentar la poca "aplicación” y capacidad para el "manejo de papeles", crítica de la que solo escapan dos entretenidos a los que el contador socorre con su propio dinero. Si el Consejo, en 1755 apoya las pretensiones de Bonavia, desde el verano de 1757 Altolaguirre cuenta con el apoyo de los Fiscales, autores de una interesante demostración de las razones que autorizan al rey a no reembolsar a Alfaro y Bonavia por no asumir las "cargas" de sus oficios venales ${ }^{29}$. Por otra parte, el contador general recomienda 
tratar bien a Tomás de Castro Colona, el mejor pero el más viejo, a quien se le debería otorgar una jubilación, y a Manuel Antonio de Ceballos, supernumerario capaz aunque poco aplicado, quien debería recibir otro destino $^{30}$. Así, parece ser que en pocos años las cuestiones individuales dejan de ser un obstáculo mayor para la definición de una planta. De hecho, Altolaguirre, invitado por el secretario del Despacho de Indias Arriaga desde 1754 para idearla, forma su plantilla en abril de 1760 sin demasiadas contestaciones ${ }^{31}$.

Este relativo consenso en torno a la posibilidad para el contador general de seleccionar a sus oficiales se derrumba al abordar sus preeminencias y facultades. En 1758, Arriaga le pide a Altolaguirre que defina la "práctica" de su oficina (horarios, número y remuneración de los oficiales, procedimientos de trabajo, relaciones entre el contador y sus oficiales y el contador y el Consejo) y la naturaleza de la documentación que necesita para trabajar. El contador general aprovecha la oportunidad para formular una lista de demandas, otras tantas críticas al Consejo, que retendría información y no reconocería las prerrogativas del contador. Éste, en opinión de Altolaguirre, debería ser "un verdadero fiscal de la real Hacienda”. Para sustentar esta calidad era sería preciso conferirle oficialmente ciertas facultades. Así, el Consejo no debe poder evacuar expedientes en que el rey tenga intereses de dinero sin pedir informe al contador: para ello, es preciso comunicarle los expedientes integrales, a fin de que tome la razón de las disposiciones adoptadas antes de devolver la documentación. Es afrentoso que no se reconozca la capacidad del contador para preservar el secreto sobre los negocios de Hacienda, "pues se debe suponer que el que obtuviere este importante empleo sabrá guardar el secreto y sigilo de los asuntos que se le fíen para cumplir en su oficio con la debida inteligencia". Por fin, debe poderse dirigir al rey por la vía reservada, "no sólo en materia de cuentas sino indistintamente sobre cualesquiera otros asuntos que se rocen o tengan conexión con el real haber". En suma, aunque Altolaguirre parece intentar hallar un acomodo designando a su Contaduría como "Contaduría del Consejo" y renunciando al proyecto de Ruiz de Porras de convertirla en "Tribunal Supremo", sí continúa asociándola a la potenciación de la vía reservada, lo que obliga a ampliar sus facultades. En su proyecto de planta, es fiel al modelo inicial cuando alude a la analogía con las Contadurías Generales creadas en 1717: el nivel de salarios debería ser similar y, como en ellas, el oficial mayor debería poder sustituir al "jefe principal de la oficina" ${ }^{32}$.

Estas reclamaciones incomodan al Consejo. Consultado en el verano de 1758, el consejero y camarista Francisco Fernández de Molinillo marca los límites enseguida, designando a Altolaguirre como "Contador del Consejo de Indias", un uso estratégico de la denominación que será constante en las dos décadas sucesivas. Asimismo, critica la amplitud de la lista de documentos informativos reclamada por el contador alegando razones prácticas -su volumen será contraproducente, causando retrasos, y el éxito requiere la buena voluntad de los virreyes y Tribunales de Cuentas, que no le parece evidente-. Pero lo más importante es la competencia directa entre Contaduría y Consejo. Primero, Fernández de Molinillo interpreta con razón la demanda de informaciones como una crítica implícita de la negligencia del Consejo y su Contaduría: contesta que éstos ya reclamaron la misma información a las oficinas de las Indias. Además, Esteban José Abaria, antiguo superintendente de la Contaduría del Consejo y presidente actual de la Casa de Contratación, hizo un magno trabajo de colección y ordenación de papeles. En segundo lugar, y sobre todo, el consejero reafirma la pertenencia de la Contaduría al Consejo

... pero pendiendo necesariamente esta oficina del mismo Consejo y que se ha de gobernar conforme a las leyes -como el mismo Contador prudentemente advierte- no sería extraño que se oyese el dictamen del mismo Consejo por si tuviere algo que decir acerca de este nuevo establecimiento ${ }^{33}$.

Por lo tanto, si la Contaduría General puede conservar documentos relativos a la venalidad de oficios, solo lo hará en su calidad de dependencia del Consejo. En cuanto a la obligación de pedir informes a la Contaduría General cada vez que "medie real interés", no debe ser sistemática, "porque no siempre es necesario respecto de que los Fiscales en cumplimiento de su oficio desempeñan la obligación y defensa de la real Hacienda". Como notan Bernard (1972, p. 124) y García Pérez (1998, p. 305), el camarista acoge asimismo con frialdad 
la demanda relativa a la vía reservada: el contador general se beneficia de ella "como cualquiera otro Ministro de Su Majestad", pero no debe convertirse en una "facultad expresa", ya que algunos contadores generales podrían abusar de ella para "apartarse de la subordinación al Consejo" ${ }^{34}$. Sería difícil ser más límpido: colocar al contador general debajo de la autoridad directa del Secretario de Indias es poner fin al control del Consejo sobre la nueva oficina.

Bernard (1972, pp. 124-126) interpreta la planta adoptada a 27 de marzo de 1760 como una "victoria" de Altolaguirre. Me parece ser, más bien, un intento de compromiso de parte de Altolaguirre y Arriaga. Se da al Contador el número de oficiales que solicitó, superior a lo propuesto por Abaria, y se eleva sustancialmente su salario, lo que le da lustre al cargo (véase el anexo 2). Por otra parte, el texto reconoce al contador general las principales facultades reclamadas por Altolaguirre: le da la dirección de la oficina y estipula que Consejo y Cámara de Indias no podrán "evacuar" ningún "expediente" sin un "informe” del contador; para ello, deberán comunicarle los expedientes completos, así como todas las cuentas procedentes de las cajas reales y tribunales de cuentas de Indias ${ }^{35}$. Cabe considerar que el reconocimiento de estas facultades es una satisfacción para Altolaguirre, debida al apoyo del ministro Arriaga. En los años sucesivos, los defensores de la Contaduría lo quieren entender así; por ello afirman que esta planta es el verdadero nacimiento de la oficina ${ }^{36}$ y la citan para defender sus prerrogativas. Sin embargo, creo que Arriaga buscó el compromiso, esforzándose por no herir al Consejo en lo más doloroso. Son significativos dos silencios del decreto: no resuelve la conflictiva cuestión de la vía reservada, como también señala García Pérez (1998, p. 305), y tampoco pormenoriza la naturaleza de la información contable y no contable a transmitir a la Contaduría. Como se encargan de demostrarle en seguida el Consejo y el contador al ministro, esta estrategia prudente es un fracaso.

Parece evidente que la publicación de la planta agravó la tensión que se percibía en 1758. En aquel entonces, todavía Fernández de Molinillo reconocía la buena voluntad de Altolaguirre. A fines de 1760, una causa nimia suscita un grave conflicto de precedencias. Al redactar una nómina de los ministros del Consejo de Indias, sus Secretarías y la Contaduría General, para reglar la distribución de bulas de la Santa Cruzada entre ellos, Altolaguirre colocó a los empleados de su oficina antes que a las Secretarías. Recibe en seguida una orden seca de José Ignacio Goyeneche, secretario de Nueva España del Consejo, quien le invita a respetar la precedencia de las Secretarías "sin réplica ni dilación", de acuerdo con las leyes y ordenanzas que cita. Se inicia así un tenso intercambio en que cada uno alega ejemplos contradictorios de las Contadurías de otros Consejos (los de Cruzada, Órdenes, Hacienda, Castilla) para defender su posición. Es reveladora la razón finalmente alegada por el Consejo y sus fiscales para justificar la preeminencia de sus Secretarías: éstas son “oficinas de mayor confianza, carácter y graduación que la Contaduría” y “el anteponerse la Contaduría es un acto puramente voluntario introducido por ella misma contra su propio hecho", o sea, un capricho. En otros términos, la Contaduría es de rango inferior y su titular no respeta los límites de sus prerrogativas ${ }^{37}$. No sorprende que, en las mismas fechas, el Consejo reproche a Altolaguirre que haya gastado dinero para costear las obras de instalación de su personal antes de solicitar permiso para ello ${ }^{38}$. Una vez más, la solución aportada por Arriaga al conflicto de preeminencias es ambivalente: manda observar "la regla que presentemente se sigue en Hacienda", pero, en este caso, Altolaguirre y los fiscales aportaron ejemplos opuestos en sus alegatos anteriores. La calidad de consejero de capa y espada supernumerario que el rey concede a Altolaguirre en abril de $1761^{39}$ probablemente llega demasiado tarde para resolver la situación, ya que estaba enfermo desde 1760.

La muerte de Altolaguirre no resuelve nada ${ }^{40}$. Domingo de Marcoleta, su oficial mayor, quien pretende sustituirle de modo automático en razón de la equivalencia entre su Contaduría General y las demás, se enfrenta a la negativa del Consejo, que le quiere dar una "habilitación". Éste, además, se dirige a él y su plantilla como "los Señores de la Contaduría General del Consejo de Indias etc.", lo que constituye un modo de recordarles su subordinación ${ }^{41}$. Por otra parte, Marcoleta se queja de que el Consejo no cumple con la obligación, definida en la planta de 1760, de transmitir a la Contaduría todos los expedientes relacionados con los reales haberes. En 1761 lamenta que solo se le habían dado unos pocos expedientes de comisos. En 
1764, indica que ni siguiera el Consejo hizo lo necesario para que todos los "tribunales de la América" (o sea, los tres Tribunales de Cuentas sitos en las Cortes virreinales, y tal vez las Contadurías de Caracas y la Habana) ${ }^{42}$ le enviaran duplicados de las cuentas fenecidas en ellos, por lo que la Contaduría no puede ejercer su tarea de fiscalización. El problema es que la Contaduría no está habilitada para reclamar estos documentos directamente a los Tribunales indianos ${ }^{43}$. Frente a Marcoleta, el secretario de Perú del Consejo, Juan Manuel Crespo, inicia lo que será la línea argumental del Consejo en los años sucesivos: la Contaduría debe dar informes, pero reduciéndolos "únicamente (...) a la individual noticia de lo que constare en esta contaduría, sin dar dictamen" ${ }^{44}$. Sin contradecir la letra de la planta, que impone informes del contador para todo asunto que tenga implicancias financieras, busca limitar su participación a la preparación de las decisiones impidiéndole formular propuestas y opiniones. No pude saber cómo se resolvieron estos conflictos. Es lícito creer, no obstante, que Arriaga no consigue imponer ninguna solución definitiva, ya que resurgen los mismos puntos de fricción entre el contador titular y el Consejo después de 1764. Uno de los factores que debilitan a la Contaduría es, sin duda, la calidad de simple oficial mayor de Marcoleta. No conocemos las razones que tuvo Arriaga para prolongar su interinato durante más de tres años. En todo caso, la designación de un titular, en la persona de Tomás Ortiz de Landazuri, a fines de 1764, parece ser la solución que halló el secretario de Indias para resolver el conflicto y dar a los negocios el curso previsto en la planta de $1760{ }^{45}$. El verosímil apoyo -señalado por Bernard (1972, p. 127) - de Fernández de Molinillo, antiguo jefe de Ortiz de Landazuri en Nueva España, a esta elección podría significar que se contó con él para servir de mediador.

\section{De Contaduría General de Indias a Contaduría General del Supremo Consejo DE INDIAS}

El nuevo contador general de Indias ocupa el oficio hasta su muerte en 1777. Su papel es decisivo, dado que, sin poner fin a todas las tensiones, consigue en algunos años que en términos generales se aplique la planta de 1760. La Contaduría recibe numerosos expedientes sobre los cuales emite informes y, al cabo de pocos años, es probable que pronuncie dictámenes. Como veremos, Ortiz de Landazuri la asocia a la iniciativa de las reformas relativas a las Indias. Cabe preguntarse cuáles son las razones de su relativo éxito. Una de ellas podría ser la legitimidad que se ganó en sus empleos anteriores en Nueva España, donde inició su trayectoria como oficial de la Secretaría del virrey en 1741-1743 y ejerció luego responsabilidades de Hacienda que le valieron la aprobación como "bueno y fiel ministro" antes de pasar a la Corte. En agosto de 1764, redactó una "Representación" sobre el virreinato del Perú, que pudo ser una forma de demostrar que su pericia no se restringía a Nueva España, a la espera de que se le diera una plaza ${ }^{46}$. El mismo verano fue invitado a participar en una junta extraordinaria de Indias sobre el comercio americano en que destacó por su gran capacidad de trabajo y su conocimiento del terreno novohispano (Delgado Ribas, 2007, pp. 260-277). Sin duda, el titular anterior, Altolaguirre, no podía alegar tanta experiencia ni oficios tan encumbrados cuando accedió al cargo en $1753^{47}$. No pretendo decir que el mayor lustre social y profesional de Ortiz de Landazuri le merezca una mayor consideración de parte del Consejo de Indias desde 1765: comprobaremos en seguida que no impresiona al tribunal. Sí podría explicar por qué es menos propenso que su predecesor a aceptar su subordinación y opta por un enfrentamiento abierto en los primeros años, convencido de su buen derecho. De hecho, sus oficiales -obviamente interesados en complacerle- enfatizan su "tesón” en la implantación de nuevas reglas contables, frente a las "dificultades y embarazos" impuestos por los nostálgicos del antiguo "sistema" ${ }^{48}$. Como sabemos, Machado Fiesco además elogia la tenacidad con que Ortiz de Landazuri defendió "las regalías de su empleo". Tal vez quepa atribuir a este empeño el apoyo que Arriaga le aporta, aunque, como veremos, no está a las alturas de las esperanzas del contador. Otra razón del éxito debería buscarse en las protecciones de que se pudo beneficiar Ortiz de Landazuri en la corte. Peralta Ruiz demuestra que Pedro Rodríguez de Campomanes le otorgó su confianza, como lo revela su participación 
en la junta extraordinaria de Indias, antes de su acceso a la Contaduría General de Indias. Tal vez se pueda decir lo mismo de Pablo Grimaldi, secretario del Despacho de Estado, quien informa al rey y a los demás secretarios del Despacho, Arriaga y el marqués de Esquilache, sobre la actividad de la junta (Peralta Ruiz, 2006, cap. 4). Ahora bien, Campomanes, Grimaldi y Esquilache son quienes en aquella década toman las principales decisiones relativas a las Indias, como la expulsión de los jesuitas, mientras que Arriaga queda en segundo plano, excluido del secreto sobre dicha expulsión (Castejón, 2014, cap. 1). El respaldo de estos tres ministros, o solo del primero, si se confirmara, podría permitir entender por qué Ortiz de Landazuri obtiene la confirmación sobre ciertas facultades. Por fin, cabe creer que las relaciones personales del contador con el Consejo de Indias evolucionaron. Así, se puede notar que los dos secretarios con los que tiene el enfrentamiento más duro en 1765-1766, Tomás de Mello, secretario de Nueva España, y Juan Manuel Crespo, secretario de Perú, dejan sus cargos en 1770 y 1766 . Sucede al segundo el marqués de los Llamos, con quien Ortiz de Landazuri convivió en la junta de $1764-1765^{49}$. Estos cambios pudieron aplacar las tensiones entre el Contador General y el Consejo.

Entretanto, en una primera fase, los objetos del conflicto confirman que todos los actores, favorables u hostiles a la creación de la Contaduría General de Indias, siguen considerando en 1765 que su creación altera en profundidad el gobierno de las Indias. El enfrentamiento más vivo dura un año, entre el verano de 1765 y la primavera de 1766. Abre el fuego una primera representación de Ortiz de Landazuri a Arriaga, a 3 de julio de 1765, en la que acusa al Consejo y a sus secretarios de no observar las disposiciones de la planta que los obligan a no evacuar expedientes sin solicitar sus informes. Estas disposiciones, asimismo, autorizan al contador a asistir a las deliberaciones sobre dichos expedientes e invitan a los secretarios a comunicarle los expedientes fenecidos. Contestan los fiscales del Consejo y sus secretarios, lo que suscita nuevas representaciones y contrarréplicas $^{50}$. El tono es beligerante. Así, Mello reprueba el "bastante fervor" de Ortiz de Landazuri, quien, en vez de dirigirse al Consejo y señalar con cortesía que echaba de menos ciertos documentos, "fue a dar una guerra tan impropria (sic) e insustancial, la que el Consejo graduará como tuviere por conveniente". Es un "agravio" a Mello -cuyo "honor" está en juego- y al Consejo -ya que el contador sugiere que tolera la inobservancia de la planta-. Para demostrar la mala fe de Ortiz de Landazuri, Mello redacta un índice de los expedientes que le comunicó, y comenta que además el contador recibe noticias sobre ellos tres veces: cuando se le pide informe, cuando registra el despacho que expide la disposición del Consejo y cuando se le transmite el expediente para que lo archive. En cuanto a Crespo, le reprocha al contador haber procedido "sin la debida reflexión y con nimia voluntariedad". De acuerdo con Mello y el Consejo, le pide que dé la lista de todos los documentos que el Consejo dejó de comunicarle, insinuando así que Ortiz de Landazuri exagera o miente. Éste replica que le es imposible elaborar una lista de los documentos cuya existencia desconoce y subraya a su vez la mala fe de sus contendientes. Además, se muestra tan herido como ellos: Crespo usó "las voces más impropias" y el Consejo empleó "duras extrañas voces". Pero peor que la afrenta personal, en su opinión, es el ataque contra "la graduación" de su empleo y su oficina. Estima en efecto que los secretarios buscan "abatir" a la Contaduría General "hasta el extremo más vergonzoso", ya que han armado desde 1760 una "oposición a todo lo que se obra por esta Contaduría cuando en nada es dependiente del Consejo”.

En esta cuestión de la subordinación de la Contaduría al Consejo y de su inclusión o no en el tribunal reside, como antes, el conflicto, pero las posturas se han endurecido. Así, Mello critica abiertamente la vía reservada, afirmando que Ortiz de Landazuri no tiene más facultades que Ruiz de Porras y Altolaguirre, quienes nunca se atrevieron a hacer representaciones directas al rey "ni menos llegaron a titularse Contadores Generales de Indias, sino del Consejo de Indias", otra pulla sobre el nombre de la nueva oficina en que repara García Pérez (1998, p. 327). Existe ya una memoria del conflicto: el actual contador -escribe Mello- excedió sus facultades al redactar dictámenes cuando solo se le pedían informes, como el Consejo se lo hizo saber años antes por medio de Crespo. A los pocos días, éste reitera el argumento. Por fin, según un resumen posterior de Machado Fiesco ${ }^{51}$, Crespo señala que ningún documento demuestra que el contador general de Indias tenga tantas competencias como los contadores generales de Valores y Distribución, lo que constituye otra forma de 
rebajar sus pretensiones. A este discurso, Ortiz de Landazuri opone una tradición consistente en consolidar la vía reservada a expensas del Consejo. Como afirma a 6 de noviembre, la planta de 1760 se inscribe en la continuidad de las disposiciones de 1717, 1747, 1748 y 1757. El contador glosa su significado de este modo:

Estas disposiciones variaron enteramente el giro y estado de la Contaduría y la que antes era una oficina inmediatamente
subordinada al Consejo - porque se trataban en él indistintamente todas las materias de Real Hacienda- se transformó en
Contaduría General de Cuentas y Real Hacienda de las Indias, sujeta y dependiente de la vía reservada, donde está radicado
el privativo conocimiento y dirección de todos los ramos que componen la de aquellos dominios, de forma que no teniendo
otro objeto, destino y funciones que el arreglo de esta y cuidado de la Real Hacienda, y estando inhibido el Consejo del
conocimiento de este ramo, solo tiene relación y conexión con el Consejo en aquellos asuntos y materias en que entiende
por vía de comisión en virtud de las órdenes con que se le encargan, y en las relaciones de sueldo, cuenta de gastos de estrados
y otras cosas de corta entidad
${ }^{2}$.

En otros términos, Ortiz de Landazuri contesta atacando: la "inhibición” del Consejo en asuntos de Hacienda, Guerra, Comercio y Navegación prevista en las disposiciones anteriores debería reservar estas cuestiones a la Secretaría de Indias y a la Contaduría General, por lo que solamente debería consultarse al Consejo para negocios de remuneraciones y cosas similares "de corta entidad". Estas exigencias deben traducirse en facultades concretas. 1) El Consejo debe transmitirle todos los expedientes de la vía reservada, en particular los relativos a arrendamientos, venalidad, asientos. 2) Todas las cuentas de las Indias, incluso las del Consulado de Cádiz y del colegio de San Telmo, deben liquidarse en la Contaduría. 3) Ésta debe poder recordar sus obligaciones a todos los oficiales reales, incluso los de los Tribunales de Cuentas, dándoles instrucciones contables. Ambas exigencias apuntan a reconocer su calidad de tribunal mayor, lo que enlaza el planteamiento de Ortiz de Landazuri con la propuesta de Ruiz de Porras. 4) El contador podrá dar dictámenes, ya que reducirle a informes sin dictamen haría de él un mero "relator". 5) Ortiz de Landazuri pide que cada contador general de Indias sea "Ministro del Consejo con voz y voto en él como lo son los de la Distribución, Valores y Millones”. Además de reconocerle un rango equivalente al de los demás contadores generales, la disposición sin duda facilitaría su acceso a la información. La conclusión es lógica: la Contaduría se deberá llamar "Contaduría General de Cuentas y Real Hacienda de las Indias y no del Consejo como hasta aquí”. Su nombre sigue siendo una petición de principios, como también nota Bernard (1972, p. 133).

Es lícito imaginar que cada campo extremó su postura para obligar al otro a concesiones, en una clásica dinámica de negociación. De hecho, aunque las posiciones parecen irreconciliables, ciertos actores dan muestras de una voluntad de acomodación. Así, se podría interpretar la propuesta de los fiscales, en abril de 1766, no por su tenor -la solución que idean atribuye al Consejo la iniciativa de consultar o no al contador-, sino por su forma. En efecto, al contrario de los secretarios, que se contentan con enunciar principios, los fiscales buscan delimitar tipos de negocios para definir su tramitación ${ }^{53}$. Aunque es poco probable que el arreglo le convenga a Ortiz de Landazuri, los actores se encaminan desde aquel entonces a un modus vivendi. En efecto, el contador general obtiene la facultad de recordar sus obligaciones a los oficiales de Hacienda de Indias, como lo atestiguan varias instrucciones contables firmadas de su mano desde el verano de $1766^{54}$ . En 1767, el rey le da un archivero y costea las obras para habilitarle un entresuelo, lo que demuestra que reconoce la magnitud de su trabajo administrativo ${ }^{55}$. Además, satisface su demanda relativa al estatuto de los contadores generales: un primer decreto (del 18 de marzo de 1767) le concede los honores de ministro de capa y espada del Consejo de Indias, y manda al Consejo a que oiga su juramento con solemnidad y lo tenga por ministro honorario, con todas las preeminencias anejas, para que tenga "la mayor condecoración del jefe para el desempeño y oficina de tal clase". Un mes después ( 23 de abril y 9 de mayo de 1767), se otorga a todos los contadores generales de Indias voz y voto en el Consejo, por lo que Ortiz de Landazuri debe volver a prestar juramento en esta calidad ${ }^{56}$. Como en 1760 , Arriaga parece eludir los puntos más conflictivos: la documentación consultada no conserva la menor huella de una disposición general sobre la facultad expresa del contador de dar dictámenes y la obligación de transmitirle todos los expedientes de la vía reservada. Sin embargo, hay avances prácticos puntuales que podrían crear una jurisprudencia. Así, en 
una apostilla a la instrucción de 1766, Ortiz de Landazuri menciona expresamente la vía reservada -envió el proyecto del texto al rey por ella para su aprobación-, una forma de afirmar sus prerrogativas ${ }^{57}$. En los años sucesivos, el contador formula propuestas de reforma para las Indias, sin limitarse a informar -como veremos abajo-, aunque no sé si usa la forma de dictámenes. Finalmente, en 1774, el rey manda que todas las cuentas de Indias se envíen directamente a la Contaduría y, al año siguiente, se estipula que ésta enviará sus informes a la Secretaría del Despacho, no al Consejo (Bernard, 1972, p. 132). Así, se quiere potenciar de modo más abierto la vía reservada. Cabe interrogarse, sin embargo, sobre el grado de aplicación de esta última medida (García Pérez, 1998, p. 335).

En todo caso, cabe hablar de un nuevo arreglo, más favorable al contador general que el de 1760 . Se reconoce el rango del titular, equiparable al de los consejeros de Indias, y por tácito consentimiento se admite que aquel se dirija por la vía reservada al rey, que envíe directivas a los oficiales de Hacienda de Indias y les reclame documentos contables. Ahora bien, su nueva calidad de consejero con voz y voto resulta ambivalente. Por una parte, le abre un franco acceso a la información: el Consejo difícilmente podrá retener expedientes sin que el contador se entere. Por otra parte, podría ser una invitación a tolerar que el Consejo continuara ocupándose de las cuestiones de gobierno de Guerra, Hacienda, Comercio y Navegación reservadas a la vía reservada. En 1771, los oficiales de Ortiz de Landazuri parecen entenderlo así cuando explican que, aunque desde el decreto de 1747 "se inhibió" al Consejo en las cuatro materias, "es bien sabido que los más de los expedientes de esta clase se agitan en el Consejo por particular remisión de Vuestra Majestad y que en ellos concurre esta oficina" 58 . En este sentido, las concesiones hechas al contador general serían la contrapartida de su aceptación de que el Consejo de Indias, lejos de limitarse al patronato real, a lo contencioso, los propios y arbitrios o la Cruzada, conservara una participación significativa en las cuestiones que se quisieron reservar al gobierno ejecutivo desde 1717. Ya sabemos que el acuerdo no les conviene a Machado Fiesco, sucesor de Ortiz de Landazuri, ni a Gálvez ${ }^{59}$. Una nota preparada para el primero confirma el tenor del arreglo, para criticarlo. Después de recordar que el Consejo se halla "inhibido del conocimiento de los cuatro ramos" citados, añade que aunque el Consejo solicita informes sobre ellos a la Contaduría; estos negocios dependen de la vía reservada. Por tanto, no deberían suponer ninguna subordinación de la Contaduría al Consejo:

su remisión al Consejo se hace por la vía reservada y el conocimiento que se la da [a la Contaduría] en ellos a consecuencia del real decreto del año de 1760 [o sea la planta de 27 de marzo], en que es visto no pende esta oficina en materia alguna del mismo tribunal para que se le intitule Contaduría del Consejo de Indias sino inmediatamente de aquella vía reservada y que la corresponde justamente no solo por lo referido en que se intitule Contaduría General de las Indias, sino porque siendo sus primeras y peculiares obligaciones la del último examen del juicio de cuentas de toda la América que es donde toma el nombre, en este ramo ningún conocimiento tiene el Consejo por especial disposición del rey ${ }^{60}$.

Otra vez, en tiempos de Gálvez y Machado Fiesco, se trataría de volver al nombre primigenio de Contaduría General de Indias. El estudio de esta nueva inflexión reclama otra monografía ${ }^{61}$. Entretanto, desde 1766-1767 la denominación de la Contaduría refleja el compromiso alcanzado por Ortiz de Landazuri: la instrucción contable de 1766 adopta la fórmula de "Contaduría General del Real y Supremo Consejo de las Indias" ${ }^{62}$. En 1774, el propio Ortiz de Landazuri hace suya la expresión. Además, en sus reclamaciones de un salario más consecuente de 1772 y 1774, aunque pormenoriza sus "fatigas", se olvida de mencionar los anteriores conflictos ${ }^{63}$. En 1771, los oficiales de la Contaduría también hacen caso omiso de ellos en su solicitud al rey -solo mencionan la resistencia de los oficiales reacios a aplicar las nuevas reglas contables ${ }^{64}-$.

El compromiso negociado no resuelve todas las inquietudes de Ortiz de Landazuri. Desde 1772, el contador general pide un sueldo comparable al de los contadores generales de España, por lo menos igual al que gozó Ruiz de Porras, y una ampliación de su plantilla ${ }^{65}$. Arriaga no accede a su demanda, probablemente por seguir fiel a su política de control de los gastos salariales (Castejón, 2014, pp. 38-41 y 206-207), por lo que el contador debe esperar al acceso de Gálvez a la Secretaría de Indias (febrero de 1776) para obtener una satisfacción parcial ${ }^{66}$. La nueva orientación, desde 1776, se puede atribuir a la convicción del nuevo 
ministro de la necesidad de elevar el número de agentes del "superior gobierno" de las Indias y remunerarlos mejor, en Madrid y en América ${ }^{67}$. Sin duda facilita su aplicación la nueva influencia que Gálvez ejerce sobre el Consejo, en tanto secretario -al poner fin a la intromisión de los demás secretarios del Despacho en las materias de Indias- y en tanto gobernador, lo que le permite colocar fieles en el tribunal (Castejón, 2014, pp. 56-78). Pero para posibilitarla, también es necesario que Gálvez y Ortiz de Landazuri se olviden de un agudo conflicto que les opuso a fines de la década de $1760^{68}$. Además de los motivos personales que lo permitirían, y que ignoro, es tentador pensar que una de las razones de este cambio es que, a la altura de 1776, Ortiz de Landazuri puede aparecer como el que coordinó una década de reformas en las Haciendas de Indias. Gálvez, por tanto, no puede prescindir de él.

\section{4. ¿UNa DiRección de las Haciendas de Indias?}

¿Qué negocios debe abrazar una Contaduría General de Indias? Para los contemporáneos, el término suele oponerse al de Contaduría Mayor. En el siglo XVIII, una vez desaparecida la Contaduría Mayor de Hacienda 69 , el contenido de "Contaduría Mayor" es el más obvio: remite al tribunal que, en última instancia, juzga las cuentas de los que manejan el dinero del rey, emitiendo los finiquitos que les habilitan para entrar en nuevos negocios una vez cobrados sus alcances, resultas y eventuales multas. Las Contadurías Generales, en cambio, se suelen describir sin emplear el vocablo tribunal, como "oficinas" encargadas de la cuenta y razón de la recaudación y la distribución de las rentas del rey ${ }^{70}$. Dicho sea en otros términos, la Contaduría Mayor ejerce un control judicial mientras que las Contadurías Generales ejercen un control administrativo, cuyo objeto es informar sobre los fondos disponibles y su uso, una definición válida tanto para las creadas en 1717 (las de Valores, Distribución y Millones) como para las instituidas para rentas particulares, cual las de Cruzada, Tabaco, Órdenes Militares o Rentas Provinciales. Por supuesto, ambas funciones se completan. Así, la Contaduría Mayor no puede pasar en cuenta ningún pago de sueldo o pensión sin certificación de los contadores generales de la distribución; asimismo, las relaciones de valores y distribución validadas por la Contaduría General de Rentas Provinciales sirven para justificar las cuentas de los administradores de estas rentas, desde su puesta en administración directa (Dubet y Solbes Ferri, en prensa, caps. 5-7). Además, para Machado Fiesco y sus oficiales, las Contadurías Generales participan plenamente en la administración de la Hacienda real, enlazando con las tareas de la antigua Contaduría Mayor de Hacienda. Así, piensan que los de Valores y de Órdenes Militares concurren en los actos de remate de arrendamiento de rentas, aunque no conocen las modalidades exactas de su participación y aunque estos Contadores confirman globalmente su idea, la realidad se revela variada según las rentas y circunstancias, dado que, a veces, el ministro de Hacienda toma la decisión antes de que se pronuncien los contadores generales $^{71}$. Si seguimos estas definiciones, por tanto, la Contaduría General de Indias debería ser ante todo una oficina de control administrativo de las Haciendas indianas, llamada además a participar en la administración de la recaudación velando sobre los intereses del rey.

No obstante, sus competencias también abarcan el control judicial en última instancia, lo que refleja un uso a veces más laxo de los términos mayor y general ${ }^{72}$. Ya Ruiz de Porras la concibió como "tribunal supremo", como vimos. En 1772, Ortiz de Landazuri confirma este papel explicando al nuevo contador mayor de Buenos Aires (figura sobre la cual volveremos) que no le compete dar finiquitos a los oficiales reales de su distrito, lo que supone que la facultad le corresponde a él ${ }^{73}$. En las mismas fechas, sus oficiales consideran que su oficina es el equivalente para las Indias de varios tribunales que se reparten un trabajo similar para la sola España peninsular ${ }^{74}$. Ortiz de Landazuri precisa la comparación al reclamar una planta más nutrida y un alza salarial y elabora para Arriaga un cuadro que sintetiza las plantas y el coste de las oficinas responsables del control de la Hacienda de España. Según este documento, en la Contaduría General de Indias están "refundidas y compendiadas cuantas contadurías mantiene Su Majestad en la corte para la cuenta y razón de 
su erario de España": hace el trabajo de la Contaduría Mayor de Cuentas, las Generales de la Distribución, de Valores, de Millones, de Rentas Generales, de Rentas Provinciales, de Salinas, de Expolios y Vacantes y de la Pólvora. Además, se ocupa de "otros gravísimos asuntos y cuentas, que para estas y aquellos hay reales oficinas particulares distintas de las expresadas, a saber de azogues, minas, papel sellado, bulas, casas de moneda, juros, censos, medias anatas, propios, arbitrios, descuentos militares, montes píos, hospitales, casas de misericordia, etc". Queda patente, concluye el contador, la miserable dotación de su oficina ${ }^{75}$. Pero lo que nos interesa aquí es la confirmación de que reúne las funciones de un alto tribunal de cuentas y de las Contadurías encargadas de tareas administrativas. Dos décadas después, al subdividirse su Contaduría General en dos, Machado Fiesco confirma la amplitud de sus funciones en una definición general de su cometido. Desde su creación, es un

Tribunal de Contaduría Mayor para unas cuentas, Contaduría General para reveer ( $\mathrm{sic}$ ) e informar sobre las que se fenecían en Indias por las Audiencias y toman y fenecen ahora por Tribunales de Cuentas y para reunir la noticia de los valores y distribución de toda la real Hacienda de Indias y servir con esta generalidad a la superior administración y gobierno de ella, y últimamente ha sido y es una especie de fiscalía general en todos los negocios directa o indirectamente tocantes a la real Hacienda que corren por el Consejo, que como he dicho son los más ${ }^{76}$.

En suma, la nueva institución reúne tres ámbitos de competencias: el control judicial en última instancia, como Contaduría Mayor, el control administrativo, como Contaduría General, y la defensa de los derechos e intereses del rey en materia de Hacienda. Los dos primeros ámbitos no la distinguen radicalmente de la Contaduría del Consejo de Indias que la precedió ${ }^{77}$. La tercera función, en cambio, abre la puerta a una participación significativa del contador general de Indias en la dirección política de las Haciendas indianas, a imagen, como creen sus titulares, de los contadores generales de la península. Quien potencia esta dimensión es Ortiz de Landazuri.

Ya Altolaguirre opinó sobre las posibles mejoras administrativas a adoptar en las Indias. Aunque se quejó de carecer de documentos fiables (por la mala voluntad del Consejo y de los actores locales), invitó al rey a volver a impulsar la venalidad municipal y anunció la redacción de proyectos de reforma del tributo y las alcabalas $^{78}$. Su sucesor se adentra en la senda abierta desde mediados de los años 1760. Su actividad pasa de los límites del control cotidiano de la actividad de los encargados del manejo del dinero del rey, cuya dinámica y objetivos, sin embargo, reforma sustancialmente, al reorganizar a la vez a los Tribunales de Cuentas y las cajas reales $^{79}$. La omnipresencia del tercer contador general es notoria. Varios historiadores hicieron hincapié en su participación en las juntas que prepararon los decretos de libre comercio de 1778. En particular, por iniciativa suya, se relanza en 1771 una reflexión que quedó en suspenso después de la junta de 1764-1765, hecho que es señal de su influencia, y, en la junta formada en tiempos de Gálvez, por sugerencia suya se decide excluir a Nueva España de la reforma ${ }^{80}$. Suya también es la iniciativa de la creación de los cargos de contador mayor de Chile, Buenos Aires y Guatemala (1767-1768), de Quito y Filipinas (1776) y la extensión de las competencias de las Contadurías de Caracas y La Habana (Bernard, 1972, p. 128; Barbier, 1980; García Baquero, 1997; Mariluz Urquijo, 2000; Orellana, 2007; Sánchez Bella, 2002). El propio Ortiz de Landazuri la reivindica ${ }^{81}$ y conviene precisar que las creaciones efectuadas en 1776 fueron proyectadas por él antes de la llegada de Gálvez ${ }^{82}$. Asimismo, Bernard, García Baquero y Sánchez Bella mencionan la incorporación al patrimonio real de las casas de moneda de Chile, Potosí y Popayán, y la reforma de la recaudación de las alcabalas y almojarifazgos de Lima y El Callao, apoyándose en una carta a Arriaga en la que el propio Ortiz de Landazuri hace alarde de estas iniciativas, al decir ser el "único autor" del pensamiento que presidió a las primeras, mientras que la reforma fiscal se hizo "a mi instancia". En la misma carta refiere "el arreglo de minas y cobro de sus quintos" en Perú y el inicio, por primera vez, de la recaudación de los novenos en Guatemala ${ }^{83}$. Igualmente se preocupa por el control del uso de los fondos recaudados; procede a reformar "indebidos sínodos de cura" en Perú ${ }^{84}$ y da numerosos informes sobre la remuneración de oficiales, el pago de gracias, las personas que pueden pretender beneficiarse de los montepíos o el gasto, excesivo en su opinión, de la flota 
de Nueva España ${ }^{85}$. Entre sus avisos sobre la remuneración de agentes del rey, tiene particular influencia su proyecto de reorganización del conjunto de las Audiencias americanas (1772), que inspirará a la política de Gálvez (Castejón, 2014, pp. 291-292). Esta actividad polifacética se completa, según el interesado, con su concurrencia "a la vista y decisión de todos los graves asuntos consultivos y ordinarios que se han tratado en el Consejo", en su calidad de consejero, y su participación - probablemente en su calidad de contador- en numerosas juntas ${ }^{86}$. Durante la cohabitación con Gálvez consolida al Contador Mayor de Chile, establece a los de Filipinas y Quito y, en 1777, supervisa o redacta la instrucción del intendente de Venezuela (Castejón, 2014, pp. 229-30, 245, 429). Asimismo, el informe que redacta en junio de 1776 sobre los salarios de todos los individuos empleados en las Haciendas de América y Filipinas le merece la aprobación real, y se aplica en $1777^{87}$.

Para formarse una idea exacta del significado y el impacto en las Indias de los proyectos de Ortiz de Landazuri, convendría poder reconstituir la génesis y aplicación de las reformas más destacadas, las relativas a la recaudación fiscal, la incorporación de las casas de moneda y las Contadurías Mayores. Entretanto, podemos interesarnos por las razones que enuncia el contador, porque dan fe de una visión coherente del proceso reformador en que participa. Él y sus oficiales están conscientes de vivir una época marcada por grandes cambios que modificaron en profundidad el gobierno de las Indias y, para ellos, se traducen ante todo en una carga de trabajo superior a lo que, suponen, conocería la anterior Contaduría. Los oficiales mencionan la creación de la intendencia de la Habana y del Consulado de Manila, la visita general de Nueva España, la expedición del Orinoco, la nueva división de límites entre Brasil y el Río de la Plata y el enorme trabajo de fiscalización de las operaciones de compensación contable entre las cajas indianas y la Tesorería General de España (complicado por el cambio entre monedas), debido a la mayor presencia de tropas en América desde la Guerra de los Siete Años ${ }^{88}$.

Ahora bien, para controlar el producto fiscal y los flujos de dinero generados por los gastos militares, Ortiz de Landazuri pretende adoptar un método afín en lo concerniente a las casas de moneda, la recaudación fiscal y las jurisdicciones contables. Se trata de poner el manejo del dinero debajo de los ojos de agentes que dependan directamente del rey -a través de la Contaduría General y la vía reservada-. Para justificar la incorporación de las casas de moneda, alega que "los dueños y substitutos de los oficios enajenados de la corona" cometían "usurpaciones y envejecidos crímenes" ${ }^{89}$. Por su parte, la exposición de los motivos que tiene el contador general para crear una Contaduría Mayor en Quito permite comprender cómo relaciona entre ellas esta reforma, la reforma fiscal (la preferencia por la administración directa), la de la rendición de cuentas y las facultades de los virreyes. Crear un contador mayor significa instituir un oficial colocado debajo de la Contaduría General de Indias e independiente del Tribunal de Cuentas de su virreinato. Se encargará de recibir las cuentas de las cajas reales y las rentas reales administradas por separado de su distrito antes de enviarlas fenecidas (pero no finiquitadas) a Madrid. Podrá elegir entre el arrendamiento y la administración directa de las rentas y deberá controlar la validez de los contratos de arrendamientos en él (Mariluz Urquijo, 2000; Orellana: 2007). Como se especifica cuando se crea al de Quito, velará sobre la aplicación de las reformas previas en la administración de las rentas ${ }^{90}$. Ortiz de Landazuri alega que tanto mediante tales creaciones como gracias al paso a la administración directa -ya en uso en Quito- busca poner fin a la malversación de los oidores: en Quito, éstos, cuando se arrendaban las alcabalas y la renta del aguardiente, recibían comisiones pagadas por los arrendatarios "voluntariamente sin rebajar el precio pactado". El contador da a entender que estos regalos podrían ser el fruto de abusos, ya que "sobre el poco acierto o mucho descuido de las Audiencias en materias de administración y cuenta y razón de los intereses reales, se disipan y malversan estos al abrigo de la distancia de los virreyes y tribunales de cuentas, como lo enseña la experiencia”. Por tanto, la creación de un contador general descrito como independiente del Tribunal de Cuentas de Santa Fe es el complemento normal de la administración directa. Se trata de privar a las Audiencias de sus gratificaciones indebidas ejerciendo un control sobre sus actividades en zonas distantes 
del Tribunal de Cuentas ${ }^{91}$. El tercer complemento, en su opinión, son las nuevas instrucciones en materia de control contable, tal vez porque las dadas a los contadores mayores son un reflejo de las instrucciones generales de 1766 y 1767 (Dubet y Sánchez Santiró, en prensa). Por fin, relaciona estas reformas con la potenciación de la superintendencia general de la Hacienda real en manos de los virreyes ${ }^{92}$. Al hacerlo, asume el proyecto de Ensenada de reforzar la vía reservada asentándola en la colaboración de la máxima autoridad de cada virreinato, a expensas de los tribunales. Así, Ortiz de Landazuri no comparte la radicalidad de Gálvez respecto a los virreyes, tal vez por tener buenas relaciones con Antonio María Bucareli, el de Nueva España (Castejón, 2014, p. 120).

El propio Ortiz de Landazuri establece un paralelo entre la situación de Quito y la "infeliz situación y decadencia en que se hallaba" la real Hacienda de Chile "cuando se creó el Contador Mayor don Silvestre García, que la ha reformado, aumentado y arreglado" ${ }^{93}$. En Chile, moviliza argumentos similares para defender al nuevo contador mayor contra los oidores, en 1774-1776 (Castejón, 2014, pp. 291-292). En Nueva Granada, como demuestra J. Pinto en este monográfico, parte de las reformas de la recaudación de rentas y del control contable empiezan durante el manejo de Ortiz de Landazuri y obedecen a objetivos políticos similares ${ }^{94}$. Ante esta propensión a aplicar las mismas razones a diversos territorios indianos y a integrar en una misma argumentación los diferentes niveles de la reforma, es lícito considerar que el contador tiene un proyecto político coherente para el gobierno de las Haciendas americanas, aunque sería útil poderlo completar examinando, por ejemplo, cómo integra en él, o no, a los intendentes.

\section{Conclusión}

Los promotores de la Contaduría General de Indias exageran la ruptura aportada, oponiendo el desorden anterior a su existencia al buen orden -recurso retórico que se utilizará contra ellos al instituir la partida doble-. No obstante, la tensa negociación mediante la cual institucionalizan la oficina confirma que su creación debilita al Consejo de Indias. Desde 1765-1766, éste debe aceptar que importantes iniciativas de reforma en materia de Hacienda procedan del contador general. Sería deseable poder evaluar las consecuencias del cambio en el trabajo del Consejo de Indias para saber hasta qué punto Ortiz de Landazuri logró aplicar el proyecto de Alberoni y Ensenada de privar al tribunal del gobierno de la Hacienda. Ahora bien, la acomodación a que llega desde mediados de los años 1770 autoriza a creer que solo lo consigue parcialmente, como sugerirá Machado Fiesco. Así, una de las claves del éxito de Ortiz de Landazuri reside en que, a la vez que se dirige a Arriaga remite informes al Consejo, el cual conserva por tanto influencia en materia de Hacienda. No sé, sin embargo, si para ciertos negocios el nuevo contador se dirige solo al ministro.

Por otra parte, además de ofrecer indicios del papel clave de la Contaduría General en el gobierno de las Haciendas indianas, este estudio permite pensar que Arriaga en gran parte delegó a su titular la tarea de idear esta política. Lo corrobora el propio Ortiz de Landazuri cuando asume algunos de los proyectos claves como suyos en sus cartas al ministro. De este modo, se prolonga mutatis mutandis la situación política que experimentara Arriaga al convivir con Esquilache y Grimaldi, según Castejón. Convendría examinar si la forma de comunicarse Ortiz de Landazuri con el ministro y con el Consejo cambia cuando Gálvez ocupa a la vez la Secretaría del Despacho y el gobierno del Consejo, y qué margen de autonomía le deja éste.

Finalmente, el análisis de la actividad de la Contaduría General de Indias en tiempos de Ortiz de Landazuri invita a matizar la idea de un aporte radicalmente nuevo de Gálvez. Éste no solo se pudo apoyar en la ingente información acumulada por la oficina sobre el producto de las rentas, el comercio lícito y el contrabando o la distribución de los salarios, pensiones y mercedes pagadas por el rey. Además, se benefició de una política que aspiraba a modificar los equilibrios locales de poder en perjuicio de las Audiencias y a favor de agentes y órganos -como los Tribunales de Cuentas y contadores mayores indianos- directamente controlados por 
una Contaduría que, a su vez, se presentaba como una emanación de la vía reservada. En cierto modo, se preparaba así el terreno a los intendentes.

\section{BibLIOgRAFÍA}

Alonso García, D. (2007). El erario del reino. Fiscalidad en Castilla a principios de la Edad Moderna (1504-1525). Valladolid: Junta de Castilla y León.

Baudot Monroy, M. (2017). La Hacienda de Marina entre la neutralidad de Fernando VI y la movilización de Carlos III en 1760. En A.J. Rodríguez Hernández, J. Arroyo Vozmediano y J. A. Sánchez Belén (coords.), Comercio, Guerra y Finanzas en una época en transición (siglos XVII-XVIII) (pp. 195-223). Valladolid: Castilla Ediciones.

Bernard, G. (1972). Le secrétariat d'Etat et le Conseil espagnol des Indes (1700-1808). Genève: Droz.

Carlos Morales, C. J. (1996). El consejo de hacienda de Castilla, 1523-1602. Patronazgo y clientelismo en el gobierno de las finanzas reales durante el siglo XVI. Valladolid: Junta de Castilla y León.

Castejón, P. (2014). Réformer la monarchie espagnole. Le système de gouvernement de José de Gálvez (1765-1787): réformes politiques, réseau et 'superior gobierno' (Tesis doctoral inédita), Université Paris I-Sorbonne, París, Francia.

Dedieu, J. P. (2000). La Nueva Planta en su contexto. Las reformas del aparato del Estado en el reinado de Felipe V. Manuscrits, 18, 113-139.

Delgado Ribas, J. M. (2007). Dinámicas imperiales (1650-1796). España, América y Europa en el cambio institucional del sistema colonial español. Barcelona: Bellaterra.

Domínguez Orta, M. (2014). El sistema de Intendencias indiano y el control de la Real Hacienda. El Virreinato del Río de la Plata (1776-1782) (Tesis doctoral inédita), Universidad Pablo de Olávide, Sevilla, España.

Donoso Anes, A. (1997). Estudio histórico de un intento de reforma en la contabilidad pública: la aplicación del método de la partida doble en las cajas reales de Indias (1784-1787). Revista española de financiación y contabilidad, 93, 1045-89.

Donoso Anes, A. (2009). Organización y funcionamiento administrativo y contable de la Real Hacienda de Indias en tiempos de los Austrias a la luz de la legislación aplicable. VI Encuentro de trabajo sobre Historia de la Contabilidad, Valladolid.

Donoso Anes, A. (2010). Documentos relativos a la implantación de la contabilidad por partida doble en las Cajas Reales de Indias (1784). Sevilla: AECA, Ilustre Colegio Central de Titulados Mercantiles y Empresariales de Madrid, Universidad de Sevilla.

Dubet, A. (2015a). Entre razón y ciencia de la Hacienda: la conflictiva construcción de un modelo de buen gobierno de la Real Hacienda en España en la primera mitad del siglo XVIII. Espacio, Tiempo y Forma, 28, 187-209.

Dubet, A. (2015b). La Hacienda Real de la Nueva Planta (1713-1726), entre fraude y buen gobierno. Madrid: Fondo de Cultura Económica.

Dubet, A. (2016a). El control del "Ministro de Hacienda" de Indias: el Marqués de Ensenada, las cuentas y las cajas americanas (1743-1754). De Computis, Revista Española de Historia de la Contabilidad, 25, 35-64.

Dubet, A. (2016b). El marqués de Ensenada y la vía reservada en el gobierno de la Hacienda americana: un proyecto de equipo. Estudios de Historia Novohispana, 55, 99-116.

Dubet, A. (en prensa), El marqués de Ensenada y el crédito del rey de España. En Gibrán Bautista Lugo (ed.), Mediación politica en las monarquias ibéricas. México: Publicaciones de la UNAM.

Dubet, A., y Sánchez Santiró, E. (en prensa). La Contaduría General de Indias y las reformas del control de las haciendas indianas antes de Gálvez (1751-1776). El aporte de Tomás Ortiz de Landazuri (título provisional).

Dubet, A., y Solbes Ferri, S. (en prensa). El rey, el ministro y el tesorero. El gobierno de la Real Hacienda en el siglo XVIII español. Madrid: Marcial Pons Historia.

Escudero, J. A. (1969). Los Secretarios de Estado y del Despacho. Madrid: Instituto de Estudios administrativos. 
Escudero, J. A. (2001). Los orígenes del Consejo de Ministros en España. La junta suprema de Estado. Madrid: Editorial Complutense (1a ed. 1979).

García-Baquero González, A. (1997). Ortiz de Landázuri y la reanudación del proceso reformista: el informe de 22 de noviembre de 1771. En J. Sarabia Viejo et al. (eds.), Entre Puebla de los Angelesy Sevilla. Estudios americanistas en homenaje alDr. José Antonio Calderón Quijano (pp.403-420). Sevilla: Escuela de Estudios Hispano-Americanos/ Universidad de Sevilla,.

García Pérez, R. (1998). El Consejo de Indias durante los reinados de Carlos III y Carlos IV. Pamplona: EUNSA.

Gómez Urdáñez, J. L. (2017). El marqués de Ensenada. El secretario de todo. Madrid: Punto de Vista Editores.

Jauregui, L. (1999). La Real Hacienda de Nueva España. Su administración en la época de los intendentes, 1786-1821. México: UNAM.

Kuethe, A. J. (2013). Cardinal Alberoni and Reform in the American Empire. En F. Eissa-Barroso \& A. Vázquez Varela (eds.), Early Bourbon Spanish America. Politics and Society in a forgotten Era (1700-1759)(pp. 23-38). Brill: Leiden-Boston.

Mariluz Urquijo, J. M. (2000). El Tribunal Mayor y Audiencia Real de Cuentas de Buenos Aires. Revista Española de Control Externo, 2(4), 129-158.

Moreno Cebrián, A. (ed.) (1983). Conde de Superunda. Relación de gobierno de Perú (1745-1761). Madrid: CSIC Instituto "Gonzalo Fernández de Oviedo".

Muñoz Pérez, J. (1947). La publicación del reglamento de comercio libre de Indias de 1778. Anuario de Estudios Americanos, IV, 615-664.

Muñoz Pérez, J. (1953). La idea de América de Campomanes. Anuario de Estudios Americanos, X, 209-264.

Nava Rodríguez, T. (2008). El poder y su precio: los orígenes de la Secretaría del Despacho de Hacienda (1700-1724). En M. V. López Cordón y J. M. Nieto Soria (eds.), Gobernar en tiempos de crisis: las quiebras dinásticas en el ámbito hispánico (1250-1808) (pp. 109-132). Madrid: Sílex..

Orellana, E. A. (2007). Evolución de la contabilidad desde los incas hasta la partida doble. Tucumán: Ediciones cooperativas.

Peralta Ruiz, V. (2006). Patrones, clientes y amigos. El poder burocrático indiano en la España del siglo XVIII. Madrid: CSIC.

Pérez Fernández Turégano, C. (2006). Patiño y las reformas de la administración en el reinado de Felipe V. Madrid: Ministerio de Defensa.

Salles Vilaseca, N. (2016). Giulio Alberoni y la dirección de la política exterior española después de los tratados de Utrecht (1715-1719) (Tesis doctoral inédita), Universidad Pompeu Fabra: Barcelona, España.

Rodríguez Villa, A. (1878). Don Cenón de Somodevilla, marqués de La Ensenada. Madrid: Librería de M. Murillo.

Sánchez Bella, I. (2002). Las reformas en Indias del secretario de Estado José de Gálvez (1776-1787). En F. Barrios Pintado (coord.), Derecho y administración pública en las Indias hispánicas. Actas del XII Congreso Internacional de Historia del Derecho Indiano (Toledo, 19 a 21 de octubre de 1998) (pp. 1517-1554). Cuenca: Ediciones de la Universidad de Castilla la Mancha,.

Sánchez Santiró, E. (2013). Corte de caja. La Real Hacienda de Nueva España y el primer reformismo fiscal de los Borbones (1720-1755). Alcances y contradicciones. México: Instituto Mora.

Sánchez Santiró, E. (2018). Ordenar las cuentas. La reforma contable de Tomás Ortiz de Landazuri (1766-1767) y su aplicación en la Real Hacienda de Nueva España. Ponencia presentada en el Seminario internacional de historia de la contabilidad pública. Ciudad de México: Instituto Mora.

Tedesco, E. (en prensa). La introducción de funcionarios reales en la administración decimal de la catedral de México (1774). Cambios en el registro contable de los diezmos y en el funcionamiento de la Contaduría. En E. Sánchez Santiró y Y. Celaya Nández (eds.), Fiscalidad e Instituciones. Los erarios regio, eclesiástico y municipal en Nueva España: coexistencia e interrelaciones. Ciudad de México: Instituto Mora.

Torres Sánchez, R. (2012). La llave de todos los tesoros. La tesorería general de Carlos III. Madrid: Sílex. 
Varela Marcos, J. (1989). El primer reglamento para el libre comercio con América: su génesis y fracaso. Anuario de Estudios Americanos, 46, 243-268.

\section{FUENTES PUBLICADAS}

Aguirre, J. De (1759), Abusos que se cometen en el manejo y dirección de todas las rentas reales, universales remedios para que logre el erario los beneficios que hoy le faltan y la monarquía española toda la gloria y esplendor que merece. Manuscrito reproducido en Antonio Valladares de Sotomayor. Semanario erudito, XI, Madrid, 1788, 36-80.

Gallardo Fernández, F. (1805). Origen, progreso y estado de las rentas de la corona de España, su gobierno y administración. Madrid: Imprenta Real, t. I.

Novísima Recopilación de las leyes de España (...) mandada formar por el señor don Carlos IV, Impresa en Madrid, 1805.

\section{Abreviaturas:}

Rs: reales

Vn: vellón

AGI: Archivo General de Indias

AGN: Archivo General de la Nación

NR: Novisima Recopilación (cfr. Fuentes publicadas)

\section{Anexo 1: los Contadores Generales de Indias entre 1751 y $1794^{95}$}

11/11/1751-16/04/1753: Joaquín Ruiz de Porras, titular.

14/04/1753-02/09/1761: Felipe de Altolaguirre, titular.

02/09/1761-24/12/1764: Domingo de Marcoleta, oficial mayor desde 28/04/1670, asume la Contaduría como interino.

24/12/1764-13/08/1777: Tomás Ortiz de Landazuri, titular.

15/08/1777-28/08/1777: Pedro de Gallareta, oficial mayor desde 1767, asume la Contaduría como interino.

28/08/1777-07/10/1794: Francisco Javier Machado Fiesco, titular.

07/10/1794: Pedro Aparici y Francisco Valencia Sáez Pontón, conde de Casavalencia, actuales Directores Generales de Indias, devienen Contadores Generales. Jubilación de Machado Fiesco.

\section{Anexo 2: cronología de las plantas}

10/11/1751: nombramiento del primer Contador General de Indias. El Gobernador del Consejo le asignará salario $^{96}$.

27/03/1760: planta de la Contaduría General (arquitectura de la oficina y facultades). La componen el contador General (50000 rs vn/año), 1 oficial mayor (15000 rs vn), 1 oficial segundo ( $12000 \mathrm{rs} \mathrm{vn}$ ), 2 terceros ( 10000 rs vn cada uno), 2 cuartos ( 8000 rs vn cada uno), 2 quintos (6000 rs vn cada uno), 2 entretenidos (3000 rs vn cada uno). Un portero del Consejo residirá en ella ${ }^{97}$. 
16/04/1760: planta de la Contaduría General (lista de oficiales) ${ }^{98}$.

18/03/1767: los Contadores Generales de Indias tendrán honores de ministros de capa y espada del Consejo, con todas sus preeminencias ${ }^{99}$.

23/04 y 09/05/1767: tendrán voz y voto en el Consejo. Su único salario será el de Contador (50000 rs vn/año) ${ }^{100}$.

20/06/1767: aprobación de la construcción de un archivo de la Contaduría. Nombramiento de un archivero en 1767101.

07/01/1773: regulación del trabajo de los oficiales ${ }^{102}$.

11/04/1776: alza del salario del Contador (55000 rs vn/año), equiparado al de los consejeros, elevado en la planta de $29 / 07 / 1773^{103}$.

16/05/1776: nueva planta de la Contaduría, con 4 oficiales más. O sea: el Contador General, un oficial mayor (22000 rs vn/año), 1 segundo (18000 rs vn), 2 terceros (15000 rs vn cada uno), 2 cuartos (13000 rs vn cada uno), 2 quintos (11000 rs vn cada uno), 2 sextos (10000 rs vn cada uno), 1 séptimo (9000 rs vn), 1 octavo (8000 rs vn), 1 noveno (7000 rs vn), un décimo (6000 rs vn), un archivero ( $8000 \mathrm{rs} \mathrm{vn}$ ), un oficial de libros (6000 rs vn ${ }^{104}$. Desde 21/05/1776, se prohíbe a los oficiales recibir comisiones particulares ${ }^{105}$.

01/02/1785: regulación del trabajo de los oficiales 106 .

1785: nueva planta ${ }^{107}$.

29/11/1787: regulación del trabajo de los oficiales ${ }^{108}$.

25/04/1790: reunión de los negocios de Hacienda y España en una misma Secretaría de Hacienda. Creación consiguiente de 3 Direcciones Generales de Rentas de Indias ${ }^{109}$.

07/10/1794: instrucción sobre la separación entre los dos departamentos de Indias de la Secretaría del Despacho de Hacienda. Los dos Directores Generales de la Hacienda de Indias en activo devienen DirectoresContadores Generales, con sendos departamentos de una misma contaduría ${ }^{110}$.

29/02/1804: subdivisión en dos Contadurías Generales ${ }^{111}$.

\section{Notas}

1 Sobre la reforma de Machado Fiesco, léanse los trabajos de Alberto Donoso Anes, en particular 1997 y 2010.

2 Dediqué 5 páginas a esta creación en Dubet, 2016 a.

3 Los dos describen las sucesivas plantas del órgano hasta fines del siglo, sus reglas y espacios de trabajo, así como la organización de sus mesas y, en el caso de García Pérez, los aranceles pagados a sus oficiales.

4 La mayor parte de los documentos están reunidos en 3 legajos del AGI, Indiferente (legs. 990, 991A y 998). En agosto de 1778, Gálvez mandó que se le diera cuenta de la forma como se aplicó en el Consejo y sus Secretarías la planta de 1760 que definía las competencias de la Contaduría (Gálvez a Miguel de San Martín Cueto, Secretario de Perú, San Lorenzo, 01/08/1778. AGI, Indiferente, leg. 998). El expediente formado se conserva en el leg. 991A.

5 Fernando VI a José de Carjaval y Lancáster, San Lorenzo, 10/11/1751 (AGI, Indiferente, 990). Bernard, 1972: 121 122. García Pérez, 1998: 301. Véanse los contadores sucesivos en el anexo 1.

6 Ruiz de Porras a Ensenada, Madrid, 16/11/1752. AGI, Indiferente 998. En esta carta comenta el proyecto de ordenanza que le remitió a 26/10/1752. Por desgracia, no encontré este proyecto.

7 Altolaguirre a Arriaga, Madrid, 25/02/1758. AGI, Indiferente, leg. 998.

8 Sobre esta construcción del ministro de Hacienda desde los años 1710s: Dubet, 2015 a.

9 Sobre sus reformas en la España peninsular: Dubet, en prensa; Gómez Urdáñez, 2017. En las Indias: Sánchez Santiró, 2013; Dubet, 2016b.

10 “tampoco procederá el Consejo a confirmar las encomiendas que sitúan los virreyes, Presidentes ni Gobernadores ni estos usarán en adelante de esta facultad, porque la reservo en mi suprema facultad”. Decreto de 20/09/1717. AGI, Indiferente, leg. 542-1.

11 Por segunda vez. Ya se suprimió en 1701-1716. Burgos Lejonagoitia, 2015, pp. 77-78 y 89-92.

12 AGI, Indiferente, leg. 542-1. NR, lib. III, tit. VI, ley V (t. II, pp. 33-35). Dedieu: 2000. Donoso Anes: 2009. Kuethe: 2013. Nava Rodríguez, 2008. Peralta Ruiz, 2006, pp. 35-36. Salles Vilaseca, 2016, pp. 171-175 
13 Afectó a los de Guerra, Estado, Órdenes y Hacienda. Archivo General de Simancas, Dirección General del Tesoro, Inventario 39, leg. 2. Gallardo Fernández, 1805, t. I, lib. I, p. 81. Sobre los de Estado y Guerra: Escudero, 1969.

14 Archivo Histórico Nacional, Fondos Contemporáneos, libro 8011, nº 304.

15 Lo explicó a posteriori Tomás Ortiz de Landazuri, cfr. infra.

16 Órdenes de 19/08/1717, 25/10/1717. AGI, Indiferente, legs. 989 y 992.

17 Véase el artículo de Sánchez Santiró en este monográfico.

18 Se conoce bien la actividad de Patiño, como Secretario de Indias, en las cuestiones de comercio y compañías, pero se dejó de lado lo relativo a la Hacienda de Indias. Pérez Fernández-Turégano, 2006.

19 Sánchez Santiró, 2013, pp. 335-7; Dubet, 2016b. En este monográfico, J. Pinto Bernal señala que ya antes de 1745 se contempló la posibilidad de aplicar en Nueva Granada la ordenanza de intendentes del equipo Alberoni de 1718.

20 Fernando VI a Carjaval y Lancáster, San Lorenzo, 10/11/1751. AGI, Indiferente, leg. 990.

21 Domingo de Marcoleta a Arriaga, Madrid, 03/10/1761. AGI, Indiferente, leg. 990.

22 Ortiz de Landazuri a Arriaga, 06/11/1765. AGI, Indiferente, leg. 998. Cit. en Dubet, 2016a, p. 47.

23 Ortiz de Landazuri a Arriaga, Madrid, 02/05/1767. AGI, Indiferente, leg. 992.

24 Cédula de 07/02/1757, que revalida los decretos de 20/01/1717, 11/09/1717 y la cédula de 18/05/1747. AGI, Indiferente, leg. 998. Marcoleta a Arriaga, Madrid, 24/12/1761. AGI, Indiferente, leg. 989. Ortiz de Landazuri a Arriaga, Madrid, 12/10/1765. AGI, Indiferente, leg. 990.

25 Conflictos pormenorizados en Dubet, 2016a, pp. 44-48. A 30/12/1752, Ruiz de Porras pide que Tomás de Castro y Colona lo sustituya como interino. Se le jubila a 16/04/1753 con salario de 60.000 reales al año. AGI, Indiferente, legs. 989 y 998. Disiento de Bernard (1972, pp. 121-122), quien toma al pie de la letra el pretexto de la vejez dado para esta jubilación.

26 Debo esta explicación a Ph. Castejón, excelente conocedor del periodo. Véase Castejón, 2014: cap. 1.

27 Machado Fiesco a Gálvez, Madrid, 03/07/1778. AGI, Indiferente, leg. 998. Machado Fiesco a Gálvez, ¿1779?. AGI, Indiferente, 990. Bernard, 1972: 133.

28 No me adentraré, en cambio, en las trayectorias individuales y las relaciones clientelares de cada uno, por concentrarme en sus estrategias de negociación y sus proyectos políticos y por carecer de elementos para completar lo que ya expusieron en particular G. Bernard, P. Castejón, A. Donoso Anes, A. García Baquero, I. Sánchez Bella y E. Sánchez Santiró en sus obras citadas en este texto.

29 Se planteó una cuestión similar al suprimir la Audiencia de Panamá en 1751, comprándose finalmente los oficios suprimidos. Castejón, 2014: 207.

30 El Consejo a Esteban José de Abaria, Madrid, 04/02/1757. Altolaguirre a Arriaga, Madrid, 29/01/1757. José Moreno y José Rojas y Contreras a Arriaga, 11/07/1757. A 25/12/1760, Bonavia sigue reclamando un reembolso. AGI, Indiferente, leg. 998. Domínguez Orta (2014, 109-109) refiere los argumentos de 1757.

31 Cartas intercambiadas entre Arriaga, Altolaguirre y Esteban José de Abaria, en 1754 y 1758-1760. AGI, Indiferente, legs. 989 y 998. La lista de los oficiales confirmada por el rey a 16/04/1760 en AGI, Indiferente, leg. 991A.

32 Dos cartas de Altolaguirre a Arriaga, Madrid, 25/02/1758. AGI, Indiferente, leg. 998. Un resumen en Bernard, 1972: 122-123. García Pérez, 302-305.

33 Fernández de Molinillo a Arriaga, Madrid, 27/04/1758. AGI, Indiferente, leg. 998.

34 Fernández de Molinillo a Arriaga, Madrid, 27/04/1758. AGI, Indiferente, leg. 998.

35 Decreto de Carlos III al duque de Alba, gobernador del Consejo, Buen Retiro, 27/03/1760. AGI, Indiferente, legs. 990 y 998.

36 Como indican los oficiales de ella al rey a 24/09/1771. AGI, Indiferente, leg. 998.

37 Cartas intercambiadas y resumen final de Arriaga al rey: AGI, Indiferente, leg. 998. Bernard, 1972: 129. Un resumen en García Pérez, 1998, p. 325.

38 Goyeneche a Altolaguirre, Madrid, 23/12/1760. AGI, Indiferente, leg. 989.

39 Fichoz.

40 Muere antes de octubre de 1761, pidiendo permiso Marcoleta para sustituirlo a 03/10/1761.

41 Marcoleta a Arriaga, Madrid, 03/10/1761, AGI, Indiferente, leg. 990.

42 Cfr. el artículo de Sánchez Santiró en este monográfico.

43 Marcoleta a Arriaga, Madrid, 27/11/1761 y 13/10/1764. AGI, Indiferente, leg. 989.

44 Crespo a Marcoleta, Madrid, 23/04/1762. AGI, Indiferente, leg. 989.

45 Se le nombra a 31/12/1764 con el mismo salario que Altolaguirre (50000 rs vn/año). AGI, Indiferente, leg. 989. Marcoleta recibe en seguida un destino superior al que tenía: pasa a ser Contador del Cargo de la Tesorería Mayor. Fichoz.

46 En particular, como secretario del Presidente de la Audiencia de Guadalajara, luchó desde 1746 contra el contrabando comercial e implantó las alcabalas en Nueva Vizcaya. Fue posteriormente Juez de Minas y Mineros, Corregidor y Teniente de Capitán General de Zacatecas, fomentando la minería (1747-1749), y, de vuelta a Guadalajara, redactó 
ordenanzas para regular nuevas actividades mineras. Alcalde de la ciudad desde 1756, regidor perpetuo desde 1757, desempeñó varias comisiones antes de pasar a la corte, en 1758, donde representó a la ciudad. En 1761, obtuvo el hábito de Santiago. Bernard, 1972: 127. Sánchez Santiró, 2018.

47 Parece haberse beneficiado de la protección de José Manso de Velasco, conde de Superunda, virrey de Perú, quien en 1746 le dio la $4^{a}$ plaza de oficial real en el Tribunal de Cuentas de Lima y le integró a la junta que definió las tarifas de las alcabalas. No sé cuánto tiempo permaneció el el Tribunal ni en Lima. Como Ortiz de Landazuri, había obtenido un hábito de Santiago, en 1745. Cfr. Superunda a Ensenada, Lima, 18/03/1746; Ensenada a Superunda, Aranjuez, 18/05/1747. AGI, Lima, leg. 1127. Moreno Cebrián, 1983: 92-93.

48 Los oficiales de la Contaduría General de Indias a Carlos III, 24/09/1771. AGI, Indiferente, leg. 998. García Pérez, 1998: 310.

49 Crespo muere en junio de 1766, sucediéndole Nicolás Mollinedo de la Cuadra, marqués de los Llamos. Mello pasa a la Cámara de Castilla. Fichoz. Hubo alguna confusión entre el marqués de los Llamos, presidente de la citada junta, y el marqués de los Llanos. Castejón (2014, p. 28) despeja la confusión a favor de Llamos.

50 A la respuesta de los fiscales (16/08), sucede una respuesta del secretario Mello (15/09), tan viva que Arriaga debe pedirle que se atenga a una carta conjunta con el otro secretario "sin particularizarse separadamente ninguno", así como las de Crespo (04/10), que motivan a su vez otras representaciones del contador (12 y 19/10,6/11) a Arriaga y respuestas directas a los secretarios, seguidas de las réplicas de éstos y, el 30/04/1766, otra intervención de los fiscales. El intercambio se distribuye entre 3 legajos: AGI, Indiferente, legs. 990, 991A, 998. Salvo indicación contraria, lo que sigue en este apartado se basa en estas fuentes. Resumen el enfrentamiento de 1765 Bernard (1972, pp. 130-132) y García Pérez (1998, pp. 326-328).

51 Fechado en 1779. AGI, Indiferente, leg. 990.

52 Ortiz de Landazuri a Arriaga, Madrid, 06/11/1765. AGI, Indiferente, leg. 998. Resumido por García Pérez, 1998, p. 328.

53 Se dividirían en 3: lo relativo a cuentas, cartas cuentas y tanteos recibido en el Consejo o la vía reservada se remitiría a la Contaduría General; para lo directamente relacionado con Hacienda por casualidad, el Consejo decidiría sobre la oportunidad de transmitirlo al contador; para lo relacionado incidentalmente con la Hacienda, sería suficiente que la Contaduría tomara la razón, haciendo un informe solo si conviniera. Resumen de Machado Fiesco, 1779. AGI, Indiferente, leg. 990. Bernard, 1972, pp. 131-132.

54 Las dadas a los oficiales de las cajas reales y los Tribunales de Cuentas a 18 de agosto de 1766 y 3 de septiembre de 1767 (Donoso Anes, 2009; Sánchez Santiró, 2018), las remitidas a los contadores de diezmos en 1773 (Tedesco, en prensa) y las de los contadores mayores creados en algunos puntos distantes de los Tribunales de Cuentas, como Buenos Aires (Orellana, 2007, pp. 184-196).

55 Ortiz de Landazuri a Arriaga, 25/07/1766. Arriaga a Ortiz de Landazuri, 20/06/1767. AGI, Indiferente, leg. 992. Cfr. nota 48 Bernard, 1972, p. 129. Sobre la negociación de este nuevo empleo, García Pérez, 1998, pp. 310-11.

56 AGI, Indiferente, leg. 990. García Pérez, 1998, p. 311. Castejón, 2014, pp. 41-42.

57 "Instrucción práctica formada por esta Contaduría General del Real y Supremo Consejo de las Indias que demuestra el Método, Reglas y Expresión con que Anualmente se deberán ejecutar los Tanteos y Cortes de Caja en todas las de la América”, Madrid, 18/08/1766. AGI, Indiferente, leg. 989-1, fol. 5. La apostilla es de 19/08. La distribución de esta instrucción y de la de 1767, asimismo, se hace por la vía reservada: Arriaga a Ortiz de Landazuri, San Ildefonso, 01/08/1766. AGI, Indiferente, leg. 992. Mello a Ortiz de Landazuri, Madrid, 23/12/1767. AGI, Indiferente, leg. 989.

58 Cfr. nota 48.

59 Cfr. supra, texto y notas 3 y 27.

60 “Apuntes para el dictamen”, ¿ 1779? AGI, Indiferente, leg. 990.

61 La resume Bernard, señalando que todavía en 1794 la denominación de la Contaduría es polémica (1972, pp. 132-134).

62 Cfr. nota 57. Los fiscales presentaron esta fórmula como un compromiso en 1766 (cfr. supra) y un resumen posterior reconoce que es una forma de buscar consenso (AGI, Indiferente, leg. 991A).

63 Ortiz de Landazuri a Arriaga, Madrid, 10/03/1772 y 02/01/1774. AGI, Indiferente, leg. 998.

64 Cfr. nota 48.

65 Ortiz de Landazuri a Arriaga, Madrid, 10/03/1772, 02/01/1774; a Gálvez, 06/03/1776. AGI, Indiferente, leg. 998. Bernard, 1972, pp. 128-129. García Pérez, 1998, p. 311.

66 Su sueldo pasa de 50 a 55000 rs vn anuales, con lo que sigue siendo inferior al de Ruiz de Porras, pero es idéntico al de los demás Consejeros de Indias, que fue equiparado al de los de Castilla desde 1773 (decreto de 10/04/1776; Bernard, 1972 , pp. 78-79). Asimismo, se dan 4 oficiales más a su oficina y se elevan los salarios de todos. Gálvez a Ortiz de Landazuri, Aranjuez, 10/04/1776; a Miguel de Múzquiz, 11/04/1776; Ortiz de Landazuri a Carlos III y a Gálvez, La Posada, 18/04/1778; cédula de nueva planta de la Contaduría, 04/05/1776; decreto de 16/05/1776. AGI, Indiferente, legs. 990 y 998 . Véase el anexo 2. 
67 La estudia Castejón, 2014, pp. 160-161 y cap. 4. Ortiz de Landazuri contribuye a esta política al elaborar un informe sobre los salarios en uso en las Indias en el que argumenta y cuantifica las elevaciones posibles: carta a Gálvez, Madrid, 28/06/1776. AGI, Indiferente, leg. 992. Sobre el alza del número de consejeros de Indias: Bernard, 1972, pp. 15-16.

68 En 1769, Ortiz de Landazuri denunció la "nulidad y ninguna fee (sic)" de los documentos contables que recibía, negándose a creer que el virrey de Croix, amigo de Gálvez, elevó el producto de las rentas, y criticó la selección de oficiales de Hacienda que hicieran estos dos. Como consecuencia debió sufrir la "atroz calumnia" de Croix, siendo solicitados Arriaga y Grimaldi para mediar en el enfrentamiento. Sánchez Bella, 2002, p. 1531. Ortiz de Landazuri a Arriaga, Madrid, 17/09/1769, AGI, Indiferente, leg. 992. El mismo al mismo, Madrid, 16/04/1770, AGI, Indiferente, leg. 990. Croix a Grimaldi, México, 30/06/1770; Arriaga a Croix, 25/08/1770. AGN México, Reales cédulas originales, vol. 97 , exp. 61 y Correspondencia virreinal, vol. 16, fols. 159-161.

69 Cohabitó con la Contaduría Mayor de Cuentas en los ss. XVI y XVII y se ocupó de la recaudación fiscal al por mayor y el control administrativo. Alonso García: 2007; Carlos Morales, 1996.

70 Diccionario de Autoridades, 1729, pp. 543-545.

71 “Apuntes para el dictamen”, ¿1779?, AGI, Indiferente, leg. 990. Machado Fiesco a Salvador de Querejazu (Contador General de Valores) y Juan José López y Villanueva (contador general de Órdenes), 11/05/1779. Respuestas de López y Villanueva, 20/05/1779, y José Rosa (por Querejazu), 04/08/1779. AGI, Indiferente, leg. 991A.

72 A 19/01/1774, Ortiz de Landazuri propone a Arriaga crear un nuevo contador general en Quito, idéntico a los contadores mayores que ya existen en Chile y Guatemala. AGI, Indiferente, leg. 992.

73 Solo desde 1794 el contador mayor, devenido entretanto Tribunal Mayor de Cuentas, puede emitir finiquitos. Mariluz Urquijo, 2000, nota 67.

74 Cfr. nota 48.

75 Mientras que las nueve Contadurías del cuadro totalizan 258 contadores y empleados y una masa salarial anual de 2.513.760 rs vn, la General de Indias no tiene "más empleados en ella que un Contador General con 50.000 rs y once oficiales con un archivero que perciben por sus sueldos anuales 95.000 rs vellón”. "Puntual y segura noticia del número de oficiales que se hallan empleados en las principales Contadurías establecidas en esta Corte para la cuenta y razón de la real Hacienda de España, siendo entre otras la Contaduría Mayor de Cuentas, las Generales de Valores, Distribución y Millones, las de Rentas Generales y Provinciales del Reino, la que se dice también General de Salinas, la de Pólvora y las de Expolios y Vacantes, con demostración de la gruesa a que ascienden los sueldos que les están señalados anualmente en cada una, como todo resulta de las relaciones formales y estados de las propias oficinas". Madrid, 02/01/1774. A 06/03/1776, Ortiz de Landazuri envía copia del documento a Gálvez, con el mismo objeto. AGI, Indiferente, leg. 998.

76 Machado Fiesco a Gardoqui, 07/11/1794. AGI, Indiferente, leg. 998.

77 Véanse Donoso Anes, 2009 y el artículo de Sánchez Santiró en este monográfico.

78 Cfr. nota 7.

79 Domínguez Orta, 2014, 106-107. Sánchez Bella, 2002. Tedesco, 2018. Examinamos la cuestión en Dubet y Sánchez Santiró, en prensa.

80 Muñoz Pérez, 1947 y 1953. Varela Marcos, 1989. Sánchez Bella: 2002; Peralta Ruiz, 2006: cap. 4; Castejón, 2014 , pp. $28,67-68,120-122,212,221,364$.

81 "En el reino de Chile, se ha creado un Contador Principal a mi representación y bajo las instrucciones que formé (...) En Buenos Aires, también se ha creado a mi solicitud otro Contador Provincial con iguales instrucciones al de Chile (...) Con total imitación a los antecedentes, se ha erigido otro en el reino de Guatemala”. Ortiz de Landazuri a Arriaga, 10/02/1772. AGI, Indiferente, leg. 998.

82 En Quito, las mismas causas que las que prevalecieron para el contador mayor de Chile invitan a crear una Contaduría General (sic) “independiente del tribunal de Santa Fe y bajo las reglas e instrucción que formé y aprobó Su Majestad para las otras”. Carta a Arriaga, Madrid, 19/01/1774. AGI, Indiferente, leg. 992. En 1771, los oficiales de la Contaduría mencionan una nueva forma dada a la administración de Filipinas en 1771. Cfr. nota 48. En 1772, Ortiz de Landazuri dice que adoptó en Filipinas, Caracas, la Habana, Santo Domingo, Puerto Rico "el mismo uniforme método" que en otras partes, sin que se aclare si se refiere a los nuevos cargos de contador mayor o a la obligación dada a todos los oficiales reales de Indias de presentar cuentas. Ortiz de Landazuri a Arriaga, 10/02/1772. AGI, Indiferente, leg. 998.

83 Bernard, 1972, p. 128. García Baquero, 1997; Sánchez Bella, 2002. Ortiz de Landazuri a Arriaga, 10/02/1772 y 02/01/1774. AGI, Indiferente, leg. 998.

84 Ortiz de Landazuri a Arriaga, 10/02/1772 y 02/01/1774. AGI, Indiferente, leg. 998.

85 Informes conservados en AGI, Indiferente, leg. 992.

86 Junta reservada sobre el establecimiento de la intendencia de Cuba, sobre "el grave punto de si se había de permitir el uso del chiringuito y extinguir el cuantioso ramo de pulques de Nueva España”, sobre la creación del nuevo consulado de comercio de Filipinas, sobre la erección de montepíos y, desde 1767, "junta secreta formada para el arreglo general de moneda, regimiento de la antigua y labor de la que se ha empezado acuñar (sic) con los nuevos sellos”. Ortiz de Landazuri a Arriaga, 10/02/1772. AGI, Indiferente, leg. 998. 
87 Ortiz de Landazuri a Gálvez, Madrid, 28/06/1776. Respuesta a 12/05/1777. AGI, Indiferente, leg. 992.

88 Cfr. nota 48

89 Cfr. nota 48

90 Como explica a posteriori el virrey José de Ezpeleta (1789-1796), "junto con esto se le encargó que reformase y pusiese en el debido orden la administración de los varios ramos de Real Hacienda, en aquellas partes, según el espíritu de las leyes y ordenanzas que no habían tenido cumplimiento por la distancia del Virrey y del Tribunal de Cuentas de esta capital”. Ezpeleta, 1989, pp. 263-4. Debo la referencia a la gentileza de Joaquín Pinto Bernal.

91 Ortiz de Landazuri a Arriaga, Madrid, 19/01/1774. AGI, Indiferente, leg. 992.

92 "porque revocada generalmente aquella práctica, radicada la superintendencia general en los virreyes y expedidas órdenes e instrucciones para que los cortes y tanteos anuales se ejecuten con asistencia del contador más antiguo de los Tribunales de Cuentas y de los Contadores Mayores provinciales donde los hay, y, donde no, de los Presidentes, gobernadores, corregidores o alcaldes mayores de districto (sic) de cada caja, ha cesado en todas partes la asistencia de los oidores y por consecuencia necesaria la gratificación o ayuda de costa que gozaban por presenciar aquel acto". Ortiz de Landazuri a Arriaga, Madrid, 19/01/1774. AGI, Indiferente, leg. 992.

93 Ortiz de Landazuri a Arriaga, Madrid, 19/01/1774. AGI, Indiferente, leg. 992.

94 La negociación de su aplicación trajo compromisos. Me indica J. Pinto Bernal que en Quito, la independencia del Contador Mayor parece atemperada en los años 1780, permitiéndose al Tribunal de Cuentas de Santa Fe que le dé directivas sobre las reglas de elaboración de unos estados de la real Hacienda. Mora de Tóvar, 1983.

95 AGI, Indiferente, legs. 989, 990, 99. Bernard, 1972: 121-129. Base de datos Fichoz, asequible en URL: http://www.f ichoz.org/home/fichoz_espanol.

96 Se le asignan 60000 rs vn/año y conserva 30000 rs vn/año al jubilarse. Desde 1753, Altolaguirre cobra 30000. AGI, indiferente, leg. 998.

97 AGI, Indiferente, legs. 990 y 998. Bernard, 1972: 125. García Pérez, 1998: 304-305. Domínguez Orta, 2014 , p. 108.

98 AGI, Indiferente, leg. 991A. Sobre su elección: Bernard, 1972, p. 125.

99 AGI, Indiferente, leg. 990.

100 AGI, Indiferente, leg. 990.

101 AGI, Indiferente, leg. 992.

102 "Distribución por negociados entre los oficiales de la Contaduría General de las Indias de todos los expedientes y demás asuntos que se despachan y tienen su curso por ella dispuesta por el Contador General don Tomás Ortiz de Landazuri, con el objeto de facilitar su más breve curso en obsequio del servicio del rey y de la causa pública”. AGI, Indiferente, leg. 990.

103 AGI, Indiferente, leg. 998. García Pérez, 1998, p. 313.

104 AGI, Indiferente, leg. 998. García Pérez, 1998, pp. 311-12. Castejón, 2014, p. 221

105 AGI, Indiferente, leg. 990.

106 "Atendiendo a la necesidad que hay de dar nuevo arreglo a la distribución de los negocios que se despachan y tienen su curso por la contaduría (...)”. AGI, Indiferente, leg. 990.

107 Por orden de Gálvez a Machado Fiesco, dada a 01/07/1785. No encontré la planta. AGI, Indiferente, leg. 988.

108 Plan de Machado Fiesco "para el uniforme gobierno de los oficiales". AGI, Indiferente, leg. 990.

109 Bernard, 1972: 136-7. García Pérez, 1998, pp. 313-15. Jauregui, 1999, p. 64. Escudero, 2001: t. I, 505-515. NR, lib. III, tit. VI, ley 16.

110 AGI, Indiferente, leg. 998. Debo a la gentileza de Ernest Sánchez Santiró una copia del decreto enviada al virrey de Perú: AGN Perú, H-3, Libro de reales órdenes desde 1769 a 1801, fols. 288-289. Bernard, 1972, pp. 137-140. García Pérez, 1998, pp. 317-21.

111 Bernard, 1972, pp. 140-143. García Pérez, 1998, pp. 321-23. 